\title{
Activity-Dependent Regulation of the K/Cl Transporter KCC2 Membrane Diffusion, Clustering, and Function in Hippocampal Neurons
}

\author{
Ingrid Chamma, ${ }^{1,2,3}$ Martin Heubl, ${ }^{1,2,3}$ Quentin Chevy, ${ }^{1,2,3}$ Marianne Renner, ${ }^{4}$ Imane Moutkine, ${ }^{1,2,3}$ \\ Emmanuel Eugène, ${ }^{1,2,3}$ Jean Christophe Poncer, ${ }^{1,2,3}$ and Sabine Lévi ${ }^{1,2,3}$ \\ ${ }^{1}$ Institut National de la Santé et de la Recherche Médicale (INSERM), Unité Mixte de Recherche en Santé 839, F-75005 Paris, France, ${ }^{2}$ Université Pierre et \\ Marie Curie, F-75005 Paris, France, ${ }^{3}$ Institut du Fer a Moulin, F-75005 Paris, France, and ${ }^{4}$ Institut de Biologie de l'Ecole Normale Supérieure, INSERM, \\ Unité 1024, Centre National de la Recherche Scientifique, Unité Mixte de Recherche 8197, F-75005 Paris, France
}

The neuronal $\mathrm{K} / \mathrm{Cl}$ transporter $\mathrm{KCC} 2$ exports chloride ions and thereby influences the efficacy and polarity of GABA signaling in the brain. KCC2 is also critical for dendritic spine morphogenesis and the maintenance of glutamatergic transmission in cortical neurons. Because KCC2 plays a pivotal role in the function of central synapses, it is of particular importance to understand the cellular and molecular mechanisms underlying its regulation. Here, we studied the impact of membrane diffusion and clustering on KCC2 function. KCC2 forms clusters in the vicinity of both excitatory and inhibitory synapses. Using quantum-dot-based single-particle tracking on rat primary hippocampal neurons, we show that KCC2 is slowed down and confined at excitatory and inhibitory synapses compared with extrasynaptic regions. However, KCC2 escapes inhibitory synapses faster than excitatory synapses, reflecting stronger molecular constraints at the latter. Interfering with KCC2-actin interactions or inhibiting F-actin polymerization releases diffusion constraints on KCC2 at excitatory but not inhibitory synapses. Thus, F-actin constrains KCC2 diffusion at excitatory synapses, whereas KCC2 is confined at inhibitory synapses by a distinct mechanism. Finally, increased neuronal activity rapidly increases the diffusion coefficient and decreases the dwell time of KCC2 at excitatory synapses. This effect involves NMDAR activation, $\mathrm{Ca}^{2+}$ influx, KCC2 S940 dephosphorylation and calpain protease cleavage of $\mathrm{KCC} 2$ and is accompanied by reduced $\mathrm{KCC} 2$ clustering and ion transport function. Thus, activity-dependent regulation of KCC2 lateral diffusion and clustering allows for a rapid regulation of chloride homeostasis in neurons.

\section{Introduction}

Fast synaptic transmission mediated by GABA type A and glycine receptors relies primarily on chloride $\left(\mathrm{Cl}^{-}\right)$ion fluxes through ligand-gated ion channels. Thus, the maintenance of intraneuronal chloride homeostasis is crucial to preserve inhibitory synaptic efficacy. Synaptic responses mediated by $\mathrm{GABA}_{\mathrm{A}}$ and glycine receptors are principally depolarizing in immature neurons and hyperpolarizing at mature stages. The progressive hyperpolarization of the reversal potential of glycine and GABA-activated cur-

Received Dec. 27, 2012; revised Aug. 20, 2013; accepted Aug. 20, 2013.

Author contributions: J.C.P. and S.L. designed research; I.C., M.H., Q.C., E.E., and I.M. performed research; M.R. contributed unpublished reagents/analytic tools; I.C., M.H., Q.C., and E.E. analyzed data; I.C., J.C.P., and S.L. wrote the paper.

This work was supported by Institut National de la Santé et de la Recherche Médicale (Avenir program to J.C.P.), the Fondation pour la Recherche Médicale (J.C.P. and S.L.), the city of Paris (program grant to J.C.P.), and the Fondation pour la Recherche sur le Cerveau (S.L.). I.C., M.H., and Q.C. were recipients of doctoral fellowships from the Université Pierre et Marie Curie. We thank J. Nabekura for kindly providing the original pEGFP-IRES-KCC2 full-length construct, D. Choquet for the homer1c-GFP construct, A. Triller for the gephyrin-mRFP construct, P. Bregestovski for the chloride sensor CFP-YFP construct, and R. M. Mège for the chicken NCAM-120 construct and primary antibody.

The authors declare no competing financial interests.

Correspondence should be addressed to Sabine Lévi, Institut National de la Santé et de la Recherche Médicale, Université Pierre et Marie Curie, Unité Mixte de Recherche en Santé 839, 17 rue du Fer a Moulin, F-75005 Paris, France. E-mail: sabine.levi@inserm.fr.

DOI:10.1523/JNEUROSCI.5889-12.2013

Copyright $\odot 2013$ the authors $\quad 0270-6474 / 13 / 3315488-16 \$ 15.00 / 0$ rents relies on the developmental upregulation of the neuronal $\mathrm{K}^{+} / \mathrm{Cl}^{-}$cotransporter $\mathrm{KCC} 2$, which extrudes intracellular chloride under resting conditions in many species (Rivera et al., 1999; Vanhatalo et al., 2005) and brain regions (Li et al., 2002; Vinay and Jean-Xavier, 2008). Although KCC2 primarily influences GABAergic transmission in cortical neurons, its aggregation in dendritic spines at excitatory synapses (Gulyás et al., 2001; Gauvain et al., 2011; Chamma et al., 2012) suggests a possible interaction with glutamate signaling. Recent studies indicate that KCC2 is critical for dendritic spine formation (Li et al., 2007; Fiumelli et al., 2013) and the function of excitatory synapses (Gauvain et al., 2011). This regulation is independent from KCC2 transport function but instead involves its interaction with the submembrane actin cytoskeleton, most probably via the adaptor protein 4.1N (Li et al., 2007; Gauvain et al., 2011). Given the pivotal role of KCC2 in both glycine/GABAergic and glutamatergic synaptic transmission, it is of critical importance to understand the cellular and molecular mechanisms underlying its regulation.

KCC2 expression and transport function are downregulated by neuronal activity under both physiological (Kaila et al., 1997; Woodin et al., 2003; Fiumelli et al., 2005; Wang et al., 2006a,b; Kitamura et al., 2008; Lee et al., 2011) and pathological conditions, such as excitotoxicity or seizures (Reid et al., 2001; Rivera et al., 2002, 2004; Huberfeld et al., 2007; Pathak et al., 2007; Wake et 
al., 2007; Li et al., 2008; Shimizu-Okabe et al., 2011). These conditions are associated with a depolarizing shift in the reversal potential of GABA responses $\left(E_{\mathrm{GABA}}\right)$ that may enhance the gain of recently active excitatory synapses in physiological conditions or contribute to alter the excitation/inhibition balance under pathological conditions. A loss of KCC2 expression and subsequent intracellular chloride accumulation has been associated with interictal activities in the hippocampus of human patients suffering mesial temporal lobe epilepsy (Huberfeld et al., 2007). However, in some neurons, KCC2 expression does not correlate with $E_{\mathrm{GABA}}$, suggesting that KCC2 transport function might be altered independently of its expression level (Huberfeld et al., 2007). Altered KCC2 oligomerization and clustering in hippocampal neurons leads to loss of KCC2 activity with no change in membrane expression (Watanabe et al., 2009), suggesting that rapid regulation of $\mathrm{KCC} 2$ at the plasma membrane may be at play to affect KCC2 function.

Here, we studied the membrane dynamics and clustering of KCC2 in hippocampal neurons and examined how these processes are modulated by normal and pathological excitatory activities. Our results suggest activity-dependent modulation of the membrane diffusion of KCC2 participates in rapid, activitydependent regulation of chloride homeostasis in neurons.

\section{Materials and Methods}

DNA constructs. The KCC2-Flag construct was generated by insertion of three Flag sequences (DYKDHDGDYKDHHIDYKDDDD) between the unique NsiI and NheI restriction sites in the second predicted extracellular loop of KCC2. An NsiI-NheI DNA fragment containing three Flag sequences was inserted in the proper reading frame between NsiI and NheI sites engineered by site-directed mutagenesis at position 631 of the rat pEGFP-IRES-KCC2 full-length (GenBank accession number U55816) construct (gift from Junichi Nabekura, Kyushu University, Fukuoka, Japan). The EGFP-IRES sequence was deleted from the construct for multiple transfection experiments with gephyrin-mRFP and homer1c-GFP chimera. Rat KCC2-C-terminal domain (CTD; amino acids 637-1116) was cloned into the pEGFP-IRES vector between XbaI and EcoRV restriction sites for bicistronic expression of KCC2-CTD and EGFP. The CTD was generated using PCR with appropriate oligonucleotides from rat pEGFP-IRES-KCC2 construct as described previously (Gauvain et al., 2011). KCC2-Flag constructs with S940 residue mutated in aspartate (S940D) or alanine (S940A) were generated with Clontech In-Fusion HD Cloning kit (Ozyme). Chicken NCAM-120 construct was provided by René Marc Mège [Institut National de la Santé et de la Recherche Médicale (INSERM), Paris, France]. To generate shRNA targeting rat $4.1 \mathrm{~N}$, a previously described small hairpin oligonucleotide sequence shown to reduce $4.1 \mathrm{~N}$ expression by $>80 \%$ (Lin et al., 2009) was inserted in a pGeneClip hMGFP vector (Promega). Rat nontarget and KCC2-specific shRNA sequences were obtained from SABiosciences (Qiagen) as described previously (Gauvain et al., 2011). All constructs were sequenced by Beckman Coulter Genomics.

Neuronal culture. Primary cultures of hippocampal neurons were prepared as described previously (Goslin et al., 1998) with some modifications of the protocol. Briefly, hippocampi were dissected from embryonic day 18 or 19 Sprague Dawley rats of either sex. Tissue was then trypsinized $(0.25 \% \mathrm{v} / \mathrm{v})$ and mechanically dissociated in $1 \times$ HBSS (Invitrogen) containing $10 \mathrm{~mm}$ HEPES (Invitrogen). Neurons were plated at a density of $2.3 \times 10^{4}$ cells $/ \mathrm{cm}^{2}$ onto 18 -mm-diameter glass coverslips (Assistent) precoated with $80 \mu \mathrm{g} / \mathrm{ml}$ poly-D,L-ornithine (Sigma-Aldrich) in plating medium composed of MEM (Sigma) supplemented with horse serum $\left(10 \% \mathrm{v} / \mathrm{v}\right.$; Invitrogen), L-glutamine $(2 \mathrm{mM})$, and $\mathrm{Na}^{+}$pyruvate ( $1 \mathrm{~mm}$ ) (Invitrogen). After attachment for $2-3 \mathrm{~h}$, cells were incubated in maintenance medium that consists of Neurobasal medium supplemented with B27 (1×), L-glutamine ( $2 \mathrm{~mm})$, and antibiotics (Invitrogen) for up to 3 weeks at $37^{\circ} \mathrm{C}$ in a $5 \% \mathrm{CO}_{2}$ humidified incubator. Each week, one-fifth of the culture medium volume was renewed.
Transfection. Neuronal transfections with KCC2-IRES-GFP, KCC2Flag, KCC2-CTD (Gauvain et al., 2011), KCC2-Flag-S940D, KCC2Flag-S940A, the shRNA sequence against rat $4.1 \mathrm{~N}$ mRNA ( $4.1 \mathrm{~N}$ shRNA) and nontarget shRNA sequence (NT shRNA), the shRNA sequence against rat KCC2 mRNA and nontarget shRNA sequence (Gauvain et al., 2011), chicken NCAM-120, gephyrin-mRFP (Hanus et al., 2006; gift from A. Triller, École Normale Supérieure, INSERM, Paris, France), and homer1c-GFP (Bats et al., 2007; gift from D. Choquet, Centre National de la Recherche Scientifique, Bordeaux, France) were done at 13-14 d in vitro (DIV) using Lipofectamine 2000 (Invitrogen) or Transfectin (BioRad), according to the instructions of the manufacturers (DNA/lipofectant ratio of $1: 3 \mu \mathrm{g} / \mu \mathrm{l}$ ), with $1 \mu \mathrm{g}$ of plasmid DNA per $20 \mathrm{~mm}$ well. The following ratios of plasmid DNA were used in cotransfection experiments: 0.5:0.25:0.25 $\mu \mathrm{g}$ for KCC2-Flag/KCC2-Flag-S940D/KCC2Flag-S940A/NCAM-120:homer1c-GFP:gephyrin-mRFP; 0.75:0.25 $\mu \mathrm{g}$ for KCC2-Flag/eGFP:eGFP; 0.75:0.25 $\mu$ g for KCC2-Flag:KCC2-CTD: eGFP; and 0.3:0.3:0.2:0.2 $\mu \mathrm{g}$ for 4.1N shRNA/NT shRNA:KCC2-Flag: homer1c-GFP:gephyrin-mRFP. Experiments were performed 7-10 d after transfection.

To test whether insertion of the Flag tag may compromise KCC2 function, COS cells were transfected with the cyan-yellow fluorescent protein (CFP-YFP) chloride sensor (Markova et al., 2008; gift from P. Bregestovski, INSERM, Marseille, France) using nanofectin (PAA Laboratories) according to the instructions of the manufacturer (DNA/nanofectin ratio of $1: 2 \mu \mathrm{g} / \mu \mathrm{l}$ ), with $10 \mu \mathrm{g}$ of plasmid DNA per $100 \mathrm{~mm}$ well. The chloride sensor was transfected either alone (for calibration) or in combination with recombinant KCC2-Flag or KCC2-WT with a ratio of 0.5:0.5 $\mu$ g.

Chloride sensor calibration and imaging. To calibrate the CFP-YFP chloride sensor in COS cells, extracellular and intracellular chloride were equilibrated using the $\mathrm{K}^{+} / \mathrm{H}^{+}$ionophore nigericin and the $\mathrm{Cl} / \mathrm{OH}$ antiporter tributyltin (Krapf et al., 1988; Trapp et al., 1996; Marandi et al., 2002; Metzger et al., 2002) as described previously (Markova et al., 2008; Waseem et al., 2010). Cells were superfused with a solution containing nigericin (10 $\mu \mathrm{M}$; Sigma), tributyltin chloride (10 $\mu \mathrm{M}$; Sigma) and the following (in $\mathrm{mm}$ ): $2 \mathrm{CaCl}_{2}, 2 \mathrm{~K}$-gluconate, $3 \mathrm{MgCl}_{2}, 10$ HEPES, 20 glucose, and $0-140 \mathrm{NaCl} / \mathrm{Na}$-gluconate, $\mathrm{pH}$ 7.4. Cells were imaged at $31^{\circ} \mathrm{C}$ in a temperature-controlled open chamber (BadController V; Luigs \& Neumann) mounted onto an Olympus IX71 inverted microscope equipped with a $60 \times$ objective [1.42 numerical aperture (NA); Olympus]. CFP and YFP were detected using Lambda DG-4 monochromator (Sutter Instruments) coupled to the microscope through an optic fiber with appropriate filters (excitation, D436/10X and HQ485/15×; dichroic, 505DCXR; emission, HQ510lp; CFP and YFP filters from Chroma Technology). Images were acquired with an ImagEM EMCCD camera (Hamamatsu Photonics) and MetaFluor software (Roper Scientific). Images were obtained with an integration time of $10 \mathrm{~ms}$ and a frequency of $0.07 \mathrm{~Hz}$. The mean fluorescence intensity of each region of interest was measured on the last 10 images of the acquisition session. Mean background fluorescence (measured from a nonfluorescent area) was subtracted and the ratio $F_{440} / F_{480}$ was determined.

Peptide treatment and pharmacology. The following peptides and drugs were used: myristoylated dynamin inhibitory peptide $(50 \mu \mathrm{M}$; Tocris Bioscience), TTX (1 $\mu \mathrm{M}$; Latoxan), NBQX (10 $\mu \mathrm{M}$; Ascent Scientific), NMDA (50 $\mu \mathrm{M}$; Ascent Scientific), D,L-AP-5 (100 $\mu \mathrm{M}$; Ascent Scientific), 4-aminopyridine (4-AP; $100 \mu \mathrm{M} ;$ Sigma), [(RS)- $\alpha$-Methyl-4carboxyphenylglycine] ( $R, S-\mathrm{MCPG})(500 \mu \mathrm{M}$; Ascent Scientific), EGTA (1.8 mM; Sigma), and PD150606 [(Z)-3-(4-Iodophenyl)-2mercapto-2-propenoic acid] (30 $\mu \mathrm{M}$; Tocris Bioscience). EGTA was prepared in $\mathrm{NaOH}(18 \mathrm{~mm})$, TTX in $2 \%$ citric acid (v/v), PD150606 in DMSO $(0.03 \% \mathrm{v} / \mathrm{v}$; Sigma), NBQX, D,L-AP-5, and $R, S-M C P G$ in equimolar concentrations of $\mathrm{NaOH}$, and NMDA, dynamin inhibitory peptide, and 4-AP in $\mathrm{H}_{2} \mathrm{O}$. Actin filaments were depolymerized with latrunculin A ( $5 \mu \mathrm{M}$; Sigma) dissolved in DMSO $(0.1 \% \mathrm{v} / \mathrm{v})$. For singleparticle tracking (SPT) experiments, neurons were preincubated in the presence of appropriate drugs at $31^{\circ} \mathrm{C}$ for $10 \mathrm{~min}$ in imaging medium (see below for composition) after quantum dot (QD) labeling. They were then used within $40 \mathrm{~min}$. For cluster imaging and electrophysiology, drugs were added directly to the culture medium for the indicated duration in a $\mathrm{CO}_{2}$ incubator 
set at $37^{\circ} \mathrm{C}$. Cells were then transferred to a recording chamber in imaging medium and used within $30 \mathrm{~min}$. To test the reversibility of $4-\mathrm{AP}$, cells were treated for $10 \mathrm{~min}$ with $4-\mathrm{AP}$, washed, and incubated for 10 or $30 \mathrm{~min}$ in imaging medium in the absence of drugs before Flag immunostaining. The imaging medium consisted of phenol red-free MEM supplemented with glucose (33 mm; Sigma) and HEPES (20 mM), glutamine (2 mM), Napyruvate $(1 \mathrm{~mm})$, and B27 $(1 \times)$ from Invitrogen.

Immunocytochemistry. The total (membrane plus intracellular) pools of KCC2-Flag (Fig. 1B,C) or endogenous KCC2 (Fig. 1D) were revealed with immunocytochemistry in fixed and permeabilized cells, whereas the membrane pool of KCC2-Flag (all other experiments) was assessed with live cell staining. Cells were fixed for $15 \mathrm{~min}$ at room temperature (RT) in paraformaldehyde (PFA; $4 \%$ w/v; Sigma) and sucrose (20\% w/v; Sigma) solution in $1 \times$ PBS. Cells were then washed in PBS and incubated for 30 min at RT in bovine serum albumin (BSA; 3\% w/v; Sigma) and goat serum (GS; 20\% v/v; Invitrogen) in PBS to block nonspecific staining. Neurons were then incubated for $1 \mathrm{~h}$ with mouse primary antibody against Flag (1:400; Sigma) or rabbit antibody against KCC2 (1:400; Sigma) in PBS supplemented with GS $(3 \% \mathrm{v} / \mathrm{v})$. After washes, cells were incubated for $45 \mathrm{~min}$ at RT with Cy3- or Cy5- conjugated goat anti-mouse antibody $(1.9 \mu \mathrm{g} / \mathrm{ml}$; Jackson ImmunoResearch) or Cy3-conjugated goat anti-rabbit antibody $(1.9 \mu \mathrm{g} / \mathrm{ml}$; Jackson ImmunoResearch) in PBS-BSA-GS blocking solution, washed, and mounted on slides with mowiol 4-88 (48 mg/ml; Sigma). For live cell staining, neurons were washed in imaging medium and incubated for $20 \mathrm{~min}$ at $4^{\circ} \mathrm{C}$ with mouse primary antibody against Flag (1:400-1:500; Sigma) in imaging medium in the absence or presence of the appropriate drugs. After washes with imaging medium, cells were fixed for 15 min with PFA and processed for immunodetection of Flag as above. Sets of neurons compared for quantification were labeled and imaged simultaneously.

Fluorescence image acquisition and analyses. Images of Figure 1 were scanned on a Leica SP5 confocal microscope using the LAS-AF program (Leica). Images were acquired using either a $40 \times / 1.25$ NA objective (stacks of 16-35 images acquired with an interval of $0.4 \mu \mathrm{m}$, voxel size of $273 \mathrm{~nm}$, and optical zoom of 1.4) or a $100 \times / 1.44$ NA objective (stacks of $26-48$ images acquired with an interval of $0.1 \mu \mathrm{m}$, voxel size of $38 \mathrm{~nm}$, and optical zoom of 4$)$. The other images of this study were acquired using a $63 \times$ objective (1.3 NA) on a Leica DM6000 upright epifluorescence microscope with a 12-bit cooled CCD camera (Micromax; Roper Scientific) run by MetaMorph software (Roper Scientific). Exposure time was determined on bright control cells to avoid pixel saturation. All images from a given culture were then acquired with the same exposure time and acquisition parameters. Quantifications were performed on images acquired with standard light microscopy using MetaMorph software (Roper Scientific). For each image, a region of interest was chosen. For KCC2-Flag cluster analyses, images were first flatten background filtered (kernel size, $3 \times 3 \times 2$ ) to enhance cluster outlines, and a userdefined intensity threshold was applied to select clusters and avoid their coalescence. Thresholded KCC2 cluster images were binarized, and binarized regions were outlined and transferred onto raw data to determine the mean KCC2-Flag cluster number, area, fluorescence intensity, and the mean fluorescence intensity per pixel within clusters. The dendritic surface area of the region of interest was measured to determine the number of clusters per $10 \mu \mathrm{m}^{2}$. For quantifications of KCC2-Flag clusters at excitatory or inhibitory synapses, only KCC2 clusters comprising at least three pixels and apposed on at least one pixel with homer1c-GFP or gephyrin-mRFP clusters were considered. For quantifications of the proportion of KCC2-Flag clusters at synapses versus extrasynaptic sites (Fig. $1 F$ ), binarized regions of excitatory or inhibitory synapses were merged to identify both types of synapses. Excitatory and inhibitory synapses are not equally distributed along dendrites, with excitatory synapses accounting for the vast majority of the total synaptic population. To take this bias into account, the relative abundance of KCC2 at each synapse subtype (Fig. $1 G$ ) was calculated by plotting the ratio of the total surface of synaptic KCC2 clusters at a given type of synapses (excitatory or inhibitory) over the total surface area occupied by either type of synapses.

Electrophysiology. Neurons were superfused with a solution containing (in mM) $125 \mathrm{NaCl}, 20$ D-glucose, $10 \mathrm{HEPES}, 4 \mathrm{MgCl}_{2}, 2 \mathrm{KCl}$, and $1 \mathrm{CaCl}_{2}$, $\mathrm{pH} 7.4$, in a recording chamber (BadController V; Luigs \& Neumann) maintained at $31^{\circ} \mathrm{C}$ on an upright microscope (BX51WI; Olympus).
Neurons were whole-cell patch clamped with a borosilicate glass pipette containing (in mM) $104 \mathrm{~K}$-gluconate, $25.4 \mathrm{KCl}, 10 \mathrm{HEPES}, 10 \mathrm{EGTA}, 2$ MgATP, $0.4 \mathrm{Na}_{3} \mathrm{GTP}$, and $1.8 \mathrm{MgCl}_{2}$, pH 7.4, and maintained at a holding potential of $-60 \mathrm{mV}$. Photolysis of caged GABA was used to elicit GABA currents at somatic or dendritic locations. Rubi-GABA ( $15 \mu \mathrm{M}$; Ascent Scientific) was added to the extracellular solution, with $2 \mathrm{~mm}$ kynurenate (Sigma), $3 \mu \mathrm{M}$ CGP52432 (3-[[(3,4-dichlorophenyl)-methyl] amino]propyl](diethoxymethyl)phosphinic acid) (Tocris Bioscience), and 1 $\mu \mathrm{M}$ TTX. Rubi-GABA was photolyzed using a digitally modulated, diode laser beam set at $405 \mathrm{~nm}$ (Omicron Deepstar; Photon Lines) delivered through a single-path photolysis head (Prairie Technologies). The diameter of the laser beam was set to $3-5 \mu \mathrm{m}$ and directed to the soma or distal dendrites of the recorded neurons. Photolysis was induced by a $5 \mathrm{~ms}$ pulse at $5-10 \mathrm{~mW}$ on the soma or $10 \mathrm{~ms}$ at $30-40 \mathrm{~mW}$ on distal dendrites $(100 \mu \mathrm{m}$ from the soma). Voltage steps of $10 \mathrm{mV}$ for $3.5 \mathrm{~s}$ each ranging from -75 to $-25 \mathrm{mV}$ were applied to the cell at least $5 \mathrm{~min}$ after break in. Laser pulses were delivered at $2.2 \mathrm{~s}$ after the onset of the voltage step to allow for stabilization of the holding current. Current-voltage $(I-V)$ relationships were computed from peak amplitudes of a series of GABA-evoked currents recorded at increasing holding potentials and repeated twice for each location (soma and dendrite). Voltages were corrected for liquid junction potential $(-14.1 \mathrm{mV})$ and voltage drop across the series resistance of the pipette. Under these experimental conditions, the expected $E_{\mathrm{GABA}}$ predicted by the Nernst equation was $-40 \mathrm{mV}$.

Live cell staining for single-particle imaging. Neurons were stained as described previously (Bannai et al., 2006). Briefly, cells were incubated for 5 min at $37^{\circ} \mathrm{C}$ with primary antibodies against Flag (mouse, 1:300; Sigma) or extracellular epitopes of NCAM-120 (rabbit, 1:40,000; gift from R. M. Mège), washed, and incubated for $5 \mathrm{~min}$ at $37^{\circ} \mathrm{C}$ with biotinylated Fab secondary antibodies (goat anti-mouse, 1:1000; goat antichicken, 1:2000; Jackson ImmunoResearch) in imaging medium. After washes, cells were incubated for 1-2 min with streptavidin-coated QDs emitting at $605 \mathrm{~nm}(0.5-1 \mathrm{nM}$; Invitrogen) in borate buffer (50 mм) supplemented with sucrose $(200 \mathrm{~mm})$.

$Q D$ imaging. Cells were imaged at $31^{\circ} \mathrm{C}$ in a temperature-controlled open chamber mounted onto an Olympus IX71 inverted microscope equipped with a $60 \times$ objective (1.42 NA; Olympus). GFP, mRFP, and QDs were detected using Lambda DG-4 monochromator coupled to the microscope through an optic fiber with appropriate filters (excitation, HQ470/40, D540/25, and D455/70; dichroic, Q495LP, 565DCLP, and 500DCXR; emission, HQ525/50, D605/55, and HQ605/20; GFP and mRFP filters from Chroma Technology; QD filters from Omega Optical). gephyrin-mRFP, homerlc-GFP images, and QD real-time recordings were acquired with ImagEM EMCCD camera and MetaView software (Roper Scientific). Real-time fluorescence images were obtained with an integration time of $30 \mathrm{~ms}$ with 1200 consecutive frames. Cells were imaged within 40 min after appropriate drug preincubation.

SPT and analyses. Single QDs were identified by their blinking property, i.e., their random alternation between emitting and non-emitting states (Alivisatos et al., 2005). Single QD tracking and reconstruction of trajectories over the recording were performed with homemade software (MATLAB; MathWorks) as described previously (Bonneau et al., 2005). The center of the fluorescence spots was determined with a spatial accuracy of $\sim 10 \mathrm{~nm}$ by cross-correlating the image with a Gaussian fit of the point-spread function (for details, see Triller and Choquet, 2008). Spots were classified as synaptic when they overlapped with gephyrin-mRFP or homer1c-GFP clusters. mRFP and GFP images were first median filtered (kernel size, $3 \times 3 \times 1$ ) to enhance cluster outlines. Then, a user-defined intensity threshold was applied to select clusters and avoid their coalescence, and a binary mask was generated. Trajectories were considered synaptic when overlapping with the mask or extrasynaptic for spots two pixels $(440 \mathrm{~nm}$ ) away from the border of the mask (Dahan et al., 2003). Values of the mean square displacement (MSD) plot versus time were calculated for each trajectory by applying the following relationship:

$\operatorname{MSD}(n \tau)=\frac{1}{N-n} \sum_{i=1}^{N-n}\left[(x((i+n) \tau)-x(i \tau))^{2}\right.$

$$
\left.+(y((i+n) \tau)-y(i \tau))^{2}\right]
$$



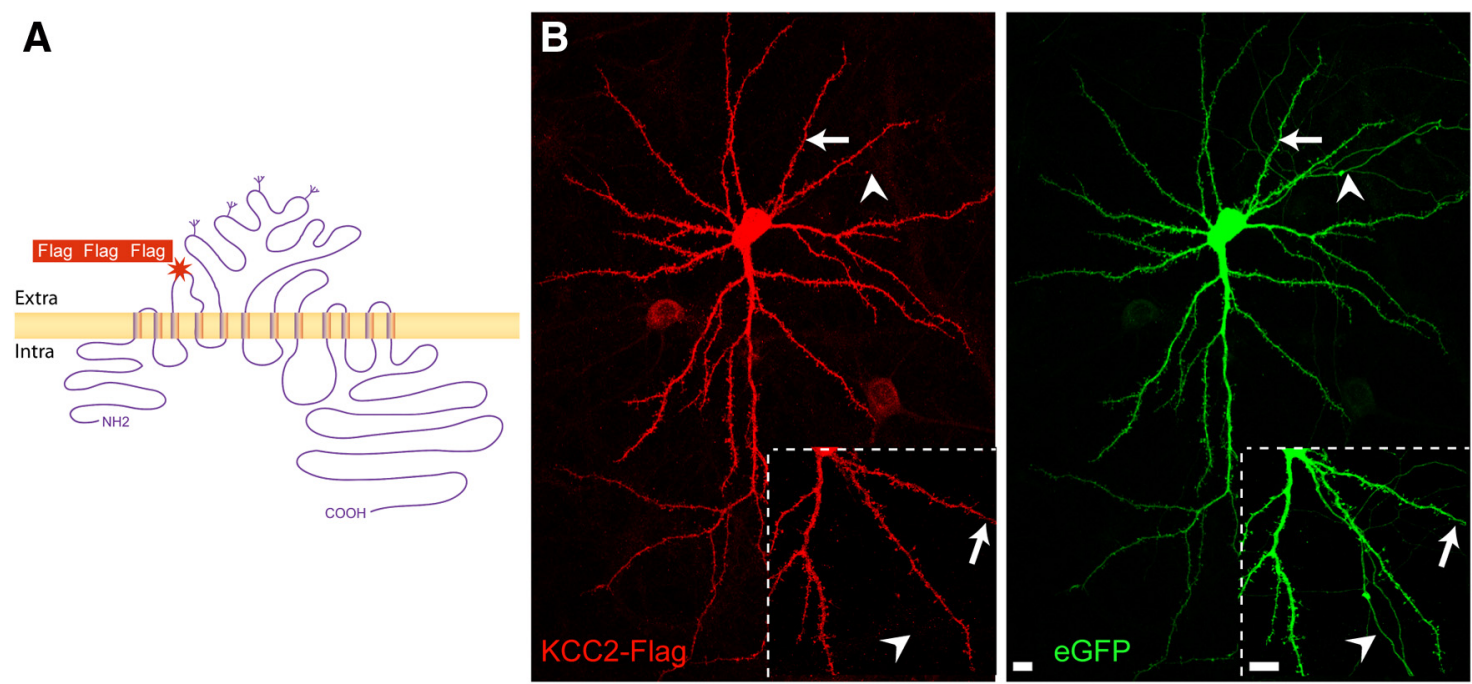

C
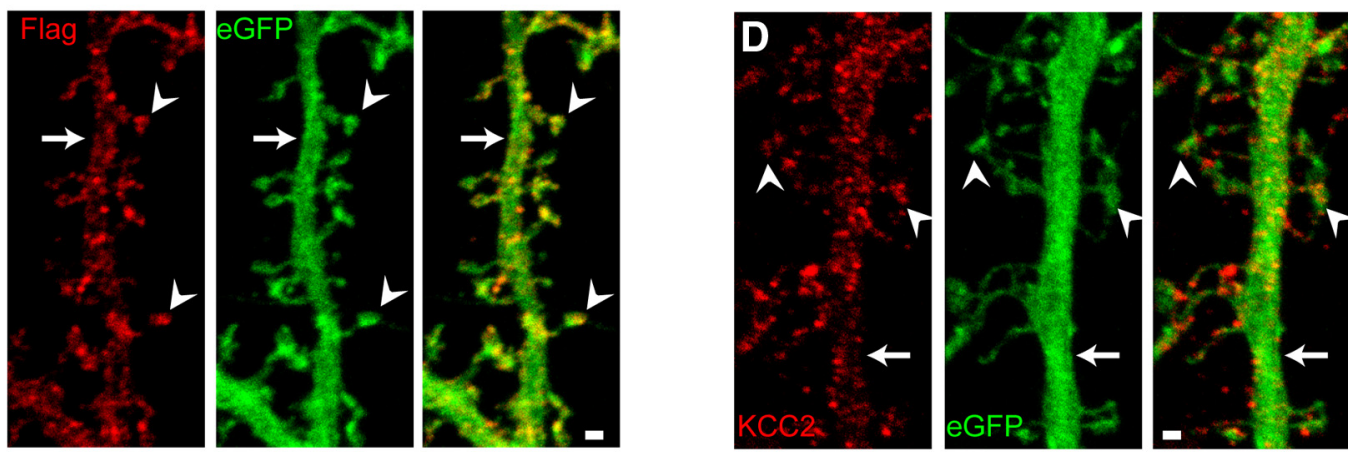

E
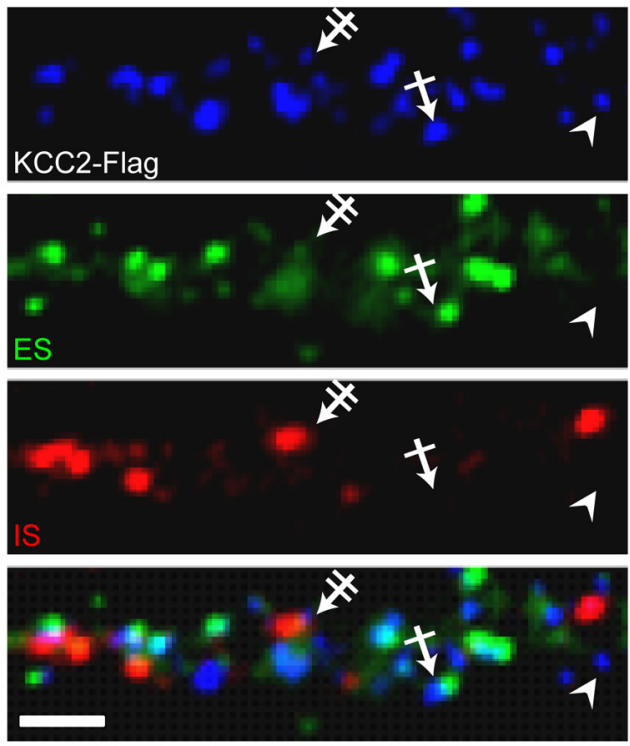

$\mathbf{F}$

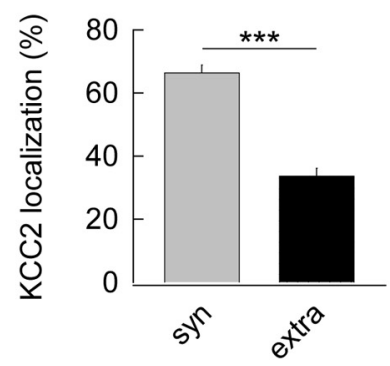

G

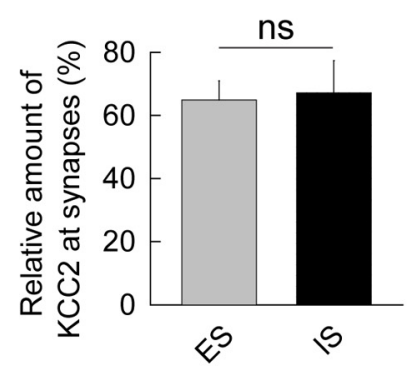

Figure 1. Recombinant, Flag-tagged KCC2 transporter is targeted to the somatodendritic neuron cell surface and preferentially accumulates at synapses. $A$, Scheme showing the site of insertion of the three Flag sequence in the second extracellular loop between transmembrane segments 3 and 4. B, Flag-tag staining (red) in permeabilized hippocampal neurons (22 DIV) transfected with KCC2-Flag and EGFP (green). Insets, Higher magnification of the regions of interest in $\boldsymbol{B}$. Scale bars, $10 \mu \mathrm{m}$. KCC2-Flag immunoreactivity is somatodendritic (arrow) and absent from axons (arrowhead). C, D, Flag (red, $\boldsymbol{C}$ ) or KCC2 (red, D) staining in neurons transfected with KCC2-Flag plus eGFP (C) or eGFP alone (D). Scale bar, $1 \mu \mathrm{m}$. Flag-tagged KCC2 forms numerous clusters in dendritic shafts (arrow) and spines (arrowheads) as the endogenous KCC2 protein. $\boldsymbol{E}-\mathbf{G}, \mathrm{KCC}$-Flag clusters at synapses. $\boldsymbol{E}$, KCC2-Flag surface staining (blue) in neurons cotransfected with homer1 C-GFP (green) and gephyrin-mRFP (red), two markers of excitatory (ES) and inhibitory (IS) synapses. Note that some KCC2-Flag clusters partially overlaid homer1c-GFP clusters (crossed arrow) or gephyrin-mRFP clusters (double crossed arrow), whereas others are associated with the extrasynaptic membrane (arrowhead). Scale bar, $2 \mu \mathrm{m} . \boldsymbol{F}$, Quantification of the proportion of KCC2-Flag membrane clusters at synapses (syn) compared with extrasynaptic membrane (extra), showing a preferential localization of KCC2 in the vicinity of synapses $\left(n=40 ; 3\right.$ cultures; ${ }^{* * *} p<$ $\left.10^{-4}\right)$. G, Comparable proportion of KCC2 at excitatory (ES) and inhibitory (IS) synapses ( $n=40 ; 3$ cultures). 
A

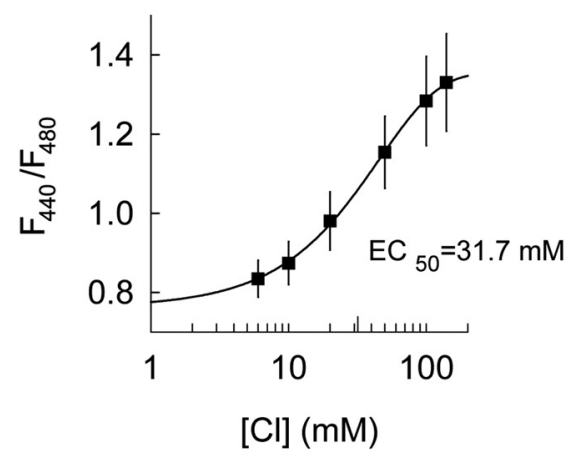

D

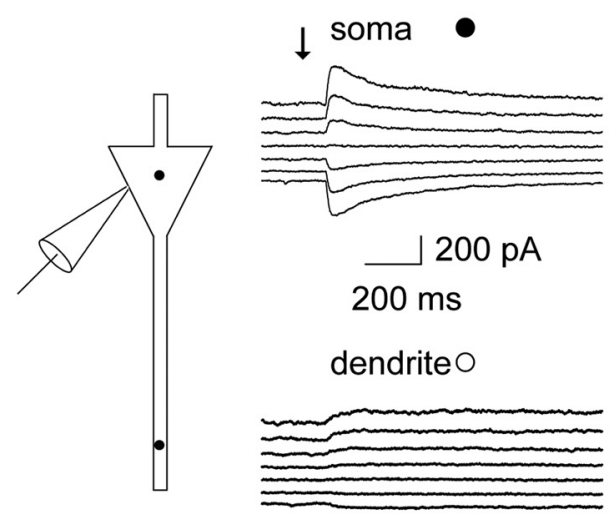

B

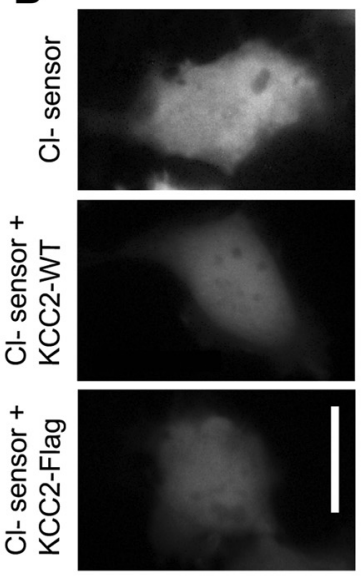

E
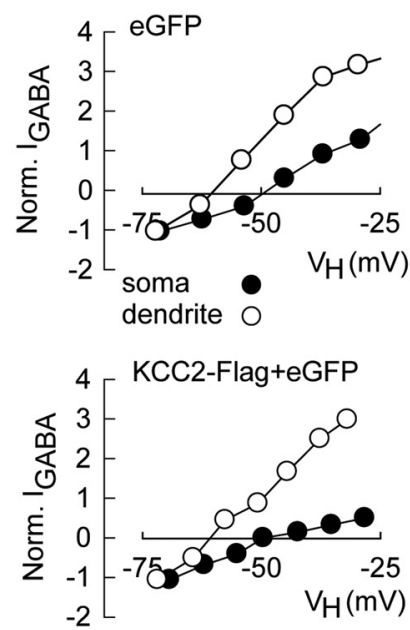

C

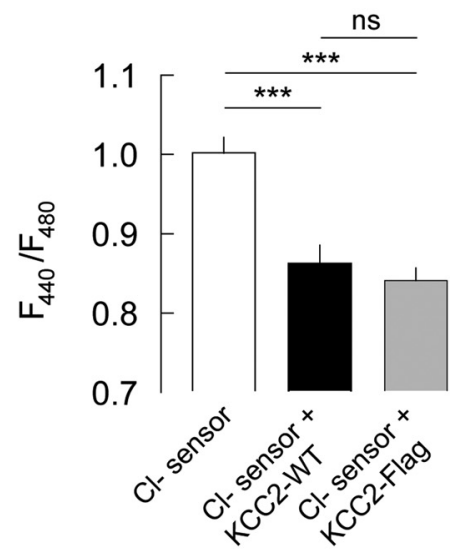

$\mathbf{F}$

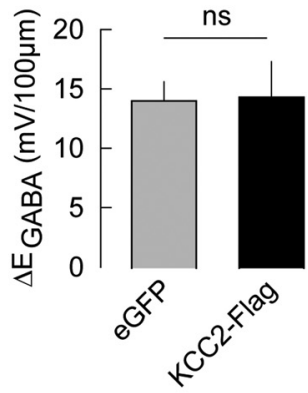

Figure 2. Recombinant KCC2-Flag is functional, and its expression does not perturb chloride extrusion in neurons. $A$, Calibration of the CFP-YFP chloride sensor ( $n=12$ for each chloride concentration, 3 cultures). B, C, Live cell ratiometric chloride imaging in COS cells transfected with the CFP-YFP chloride sensor (Cl ${ }^{-}$sensor) alone or in combination with WT (KCC2-WT) or Flag-tagged KCC2 (KCC2-Flag). B, Images show the $F_{440} / F_{480}$ fluorescence ratio. Scale bar, $20 \mu \mathrm{m}$. C, Quantifications showing significant $\left({ }^{* * *} p<10^{-3}\right)$ decrease in the CFP/YFP ratio in cells expressing the $\mathrm{Cl}^{-}$sensor in combination with $\mathrm{KCC} 2-\mathrm{WT}$ or KCC2-Flag versus cells expressing the chloride sensor alone. $\mathrm{Cl}^{-}$sensor, $r=1.0 \pm 0.02, n=51 ; \mathrm{KCC} 2-\mathrm{WT}, r=0.86 \pm 0.03, n=$ $53 ; \mathrm{KCC} 2-$ Flag, $r=0.83 \pm 0.02, n=53$, four cultures. No significant difference between cells expressing WT or Flag-tagged KCC2 $\left(p=7 \times 10^{-2}\right)$ demonstrating that Flag-tag insertion in the second predicted extracellular loop does not compromise KCC2 function. $\boldsymbol{D}-\boldsymbol{F}$, No effect of KCC2-Flag expression on chloride export estimated from the somatodendritic $E_{G A B A} g r a d i e n t$. $\boldsymbol{D}, \boldsymbol{E}$, Representative currents at voltage steps ranging from -75 to $-25 \mathrm{mV}$ during Rubi-GABA uncaging at somatic and dendritic sites $(\boldsymbol{D})$ and normalized $I-V$ relationships $(\boldsymbol{E})$. Note the leftward shift in $I-V$ relationships of dendritic versus somatic GABA currents. $F$, Mean somatodendritic $E_{\text {GABA }}$ gradient from seven (eGFP) and nine (KCC2-Flag) cells.

(Saxton and Jacobson, 1997), where $\tau$ is the acquisition time, $N$ is the total number of frames, and $n$ and $i$ are positive integers, with $n$ determining the time increment. For simple, two-dimensional Brownian mobility, the MSD as a function of time is linear with a slope of $4 D$, where $D$ is the diffusion constant. If the MSD as a function of time tends to a constant value $L$, the diffusion is confined in a domain of size $L$. Diffusion coefficients $(D)$ were calculated by fitting the first four points without origin of the MSD versus time curves with the following equation: $\operatorname{MSD}(n \tau)=4 D n \tau+b$, where $b$ is a constant reflecting the spot localization accuracy. The area in which diffusion is confined can be estimated by fitting the MSD as a function of time with the following formula:

$$
\operatorname{MSD}(n d t)=\frac{L^{2}}{3}\left(1-\exp \left(-\frac{12 D n d t}{L^{2}}\right)\right)+4 D_{\text {mac }} n d t,
$$

where $L^{2}$ is the confined area in which diffusion is restricted, and $D_{\text {mac }}$ is the diffusion coefficient on a long timescale (Kusumi et al., 1993). The size of the confinement domain was defined as the side of a square in which diffusion is confined (Kusumi et al., 1993). For details, see Ehrensperger et al. (2007)). Synaptic dwell time (DT) was defined as the dura- tion of detection of QDs at synapses on a recording divided by the number of exits as detailed previously (Charrier et al., 2006; Ehrensperger et al., 2007). DTs $\leq 5$ frames ( $150 \mathrm{~ms})$ were not retained.

Statistics. Means are shown \pm SEM, and median $D$ values are indicated with their interquartile range (IQR, 25-75\%). Means were compared using the nonparametric, Mann-Whitney rank-sum test unless stated otherwise using SigmaStat software (SPSS). Cumulative distributions and median $D$ values were compared using the Kolmogorov-Smirnov test under StatView (SAS). Differences were considered significant for $p$ values $<5 \%$.

\section{Results}

Normal membrane traffic and function of Flag-tagged KCC2 in neurons

QD-based SPT experiments require that antibodies coupled to fluorescent probes bind to the membrane protein of interest. In the absence of a reliable antibody targeting an extracellular epitope of KCC2, we designed a recombinant KCC2 transporter Flag-tagged (KCC2-Flag) within its second predicted extracellu- 
A

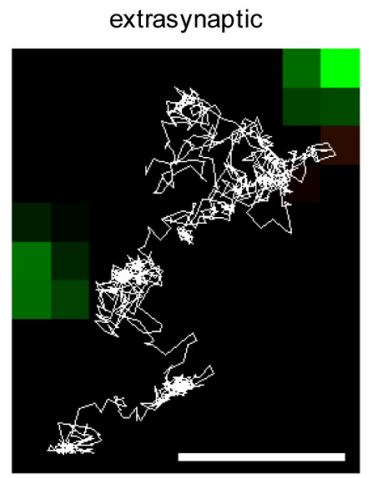

B

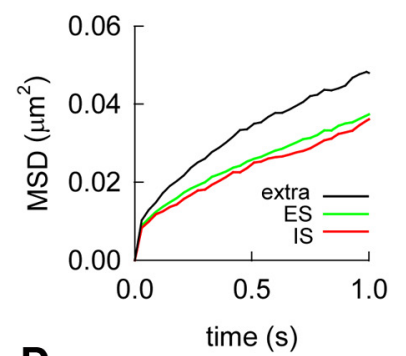

D

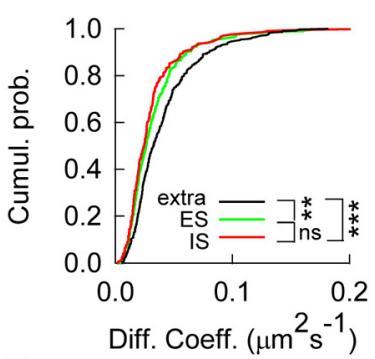

$\mathbf{F}$

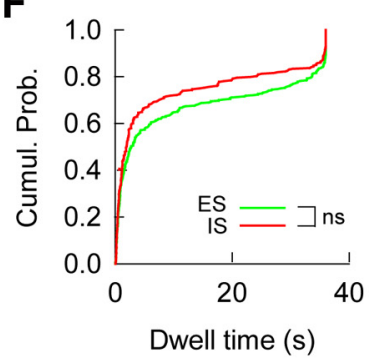

ES

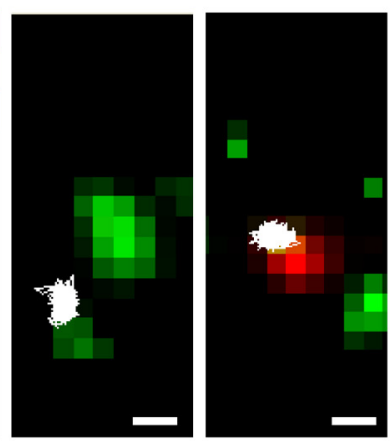

C

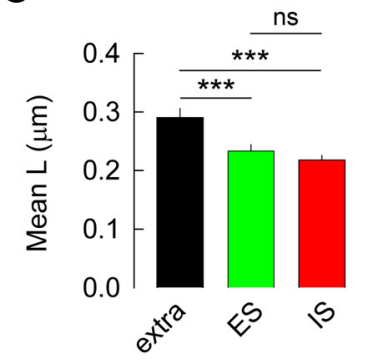

E

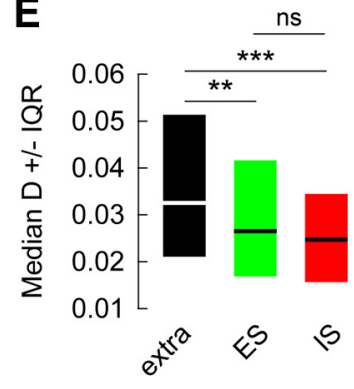

G

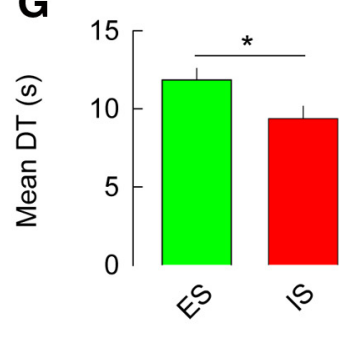

Figure 3. Membrane dynamics of the KCC2 transporter studied with QD-based SPT. $A$, Representative trajectories (white) of QD-bound Flag-tagged recombinant $\mathrm{KCC} 2$ in extrasynaptic membrane (1014 frames, $D=3 \times 10^{-2} \mu \mathrm{m}^{2} \mathrm{~s}^{-1}$ ), at excitatory synapses (1002 frames, $D=$ $\left.2 \times 10^{-2} \mu \mathrm{m}^{2} \mathrm{~s}^{-1}\right)$, and at inhibitory synapses (773 frames, $\left.D=4 \times 10^{-2} \mu \mathrm{m}^{2} \mathrm{~s}^{-1}\right) . Q D$ trajectories (white) were overlaid with fluorescent clusters of recombinant homer1c-GFP (green) and gephyrin-mRFP (red) to identify excitatory (ES) and inhibitory (IS) synapses, respectively. Scale bars, $1 \mu \mathrm{m}$. B, Time-averaged MSD functions of extrasynaptic QDs (black), QDs at excitatory synapses (green), and QDs at inhibitory synapses (red). The MSD versus time relationship for extrasynaptic trajectories shows a steeper initial slope, suggesting that trajectories were less confined. $C$, Decreased size of the confinement domain $L$ for synaptic QDs showing increased confinement $\left.{ }^{* * *} p<10^{-3}\right) \cdot \boldsymbol{D}, \boldsymbol{E}$, Cumulative probabilities (D) and median values $\pm 25-75 \%$ IQR $(E)$ of QD diffusion coefficients D in extrasynaptic membrane (black) or at excitatory (green) or inhibitory (red) synapses. Note the reduced diffusion at synapses ${ }^{* *} p=$ $\left.2 \times 10^{-3},{ }^{* * *} p<10^{-3}\right)$. F, Cumulative probability plots of KCC2-Flag DTs are shifted toward higher values at excitatory synapses $\left(p=6 \times 10^{-2}\right)$. G. Mean DTs at excitatory synapses (green) and at inhibitory synapses (red) showing increased DT of KCC2-Flag at excitatory synapses $\left({ }^{*} p<5 \times 10^{-2}\right)$.

Table 1. Diffusion properties of KCC2-Flag at excitatory and inhibitory synapses

\begin{tabular}{|c|c|c|c|}
\hline Location & $\begin{array}{l}\text { Median } \\
D\left(10^{-2} \mu \mathrm{m}^{2} \mathrm{~s}^{-1}\right)\end{array}$ & Mean $L(\mathrm{~nm})$ & Mean DT (s) \\
\hline ES & $2.7(281)$ & $237.39 \pm 12.66(212)$ & $11.9 \pm 0.8(380)$ \\
\hline IS & $2.5(202)$ & $221.03 \pm 8.90(142)$ & $9.4 \pm 0.8(288)$ \\
\hline Extra & $3.3(367)$ & $299.62 \pm 18.27(279)$ & n.d. \\
\hline
\end{tabular}

Quantifications from 49 cells and five independent experiments. Numbers in parentheses indicate the numbers of QDs analyzed. ES, QDs at excitatory synapses; IS, QDs at inhibitory synapses; Extra, QDs at extrasynaptic sites; n.d., not determined. Mean $L$ and DT values are shown \pm SEM.

lar loop between transmembrane domains 3 and 4 (see Materials and Methods; Fig. 1A). We first examined whether the insertion of the Flag tag may alter membrane targeting and cellular distribution of KCC2. Primary cultures of hippocampal neurons were transfected at 14 DIV with the recombinant KCC2-Flag transporter and eGFP and processed at 22 DIV for immunolabeling on fixed and permeabilized cells using an anti-Flag antibody. KCC2Flag was targeted to the somatodendritic domain (Fig. 1B) and excluded from axons (Fig. 1B), as observed for the endogenous transporter (data not shown; Williams et al., 1999; Gulyás et al., 2001; Hübner et al., 2001; Vale et al., 2005; Blaesse et al., 2006; Szabadics et al., 2006; Takayama and Inoue, 2006; Belenky et al., 2008; Bartho et al., 2009; Baldi et al., 2010). At the subcellular level, KCC2-Flag formed numerous clusters in dendritic shafts and spines (Fig. 1C), similar to the endogenous transporter (Fig. 1D; Lee et al., 2007; Watanabe et al., 2009; Gauvain et al., 2011). Live cell Flag immunolabeling to selectively stain KCC2-Flag at the surface revealed that the recombinant transporter was targeted to the plasma membrane (Fig. 1E). These results indicate that the Flag-tagged transporter traffics normally to the somatodendritic membrane and that the recombinant protein is present in large amounts at the cell surface.

We showed previously with confocal microscopy that endogenous KCC2 clusters are detected in the vicinity of excitatory and inhibitory synapses (Chamma et al., 2012), and electron microscopy studies indicate that its localization might be perisynaptic and/or postsynaptic (Gulyás et al., 2001; Bartho et al., 2004; Blaesse et al., 2006; Takayama and Inoue, 2006). Therefore, we evaluated the abundance of surface KCC2-Flag clusters at synapses in neurons cotransfected with GFP-coupled homerlc and mRFP-coupled gephyrin to label excitatory and inhibitory synapses, respectively (Hanus et al., 2006; Ehrensperger et al., 2007). KCC2 clusters were considered synaptically located when overlapping with homer1c-GFP or gephyrin-mRFP clusters and extrasynaptic when localized at least two pixels $(286 \mathrm{~nm}$ ) away from synaptic markers. Surface KCC2-Flag clusters showed partial colocalization with synaptic markers and were also detected in extrasynaptic regions (Fig. 1E). Quantifications revealed that $66.4 \pm 2.5 \%$ surface KCC2-Flag clusters were localized at synapses (i.e., independent of their localization at excitatory or inhibitory synapses; see Materials and Methods; Fig. $1 F$ ), showing a preferential association of the transporter with synaptic compartments. The apparent preferential synaptic localization of KCC2Flag was not attributable to a sampling bias because synapses occupy only $11.5 \pm 1.0 \%(n=14)$ of total dendritic surface. Furthermore, a similar proportion of surface KCC2-Flag clusters localized at glutamatergic and GABAergic synapses (see Materials and Methods; Fig. 1G). Thus, KCC2-Flag accumulates at both excitatory and inhibitory synapses.

To test whether insertion of the Flag tag may compromise KCC2 function, we measured chloride extrusion in COS cells using ratiometric fluorescence imaging of a CFP-YFP chloride sensor (Markova et al., 2008; Waseem et al., 2010). We first cali- 
A

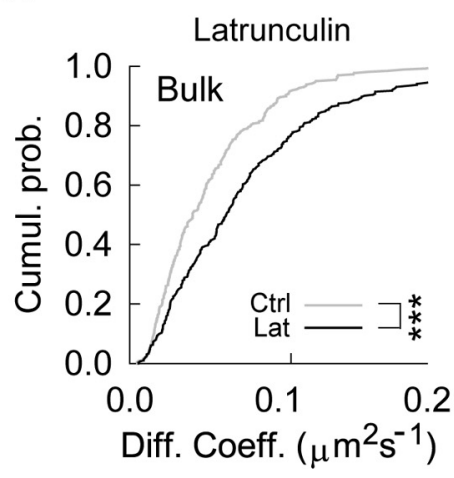

D

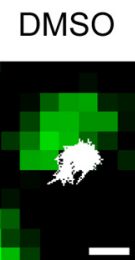

G

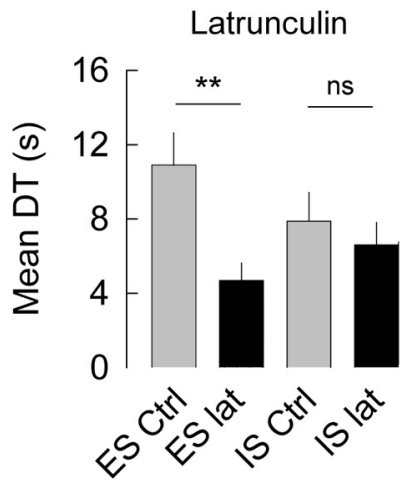

B

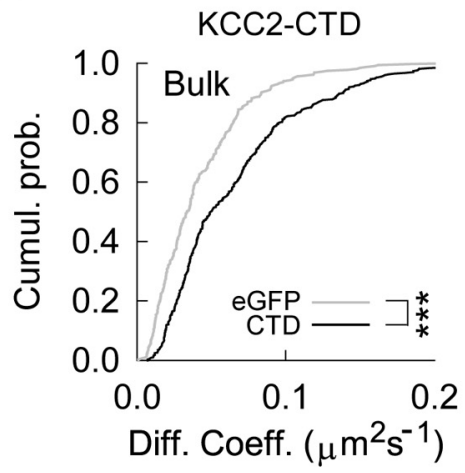

E

GFP

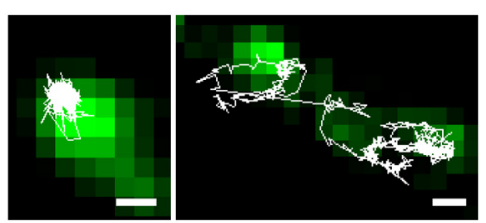

H

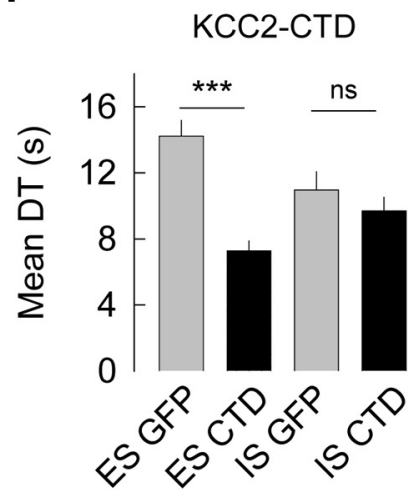

C

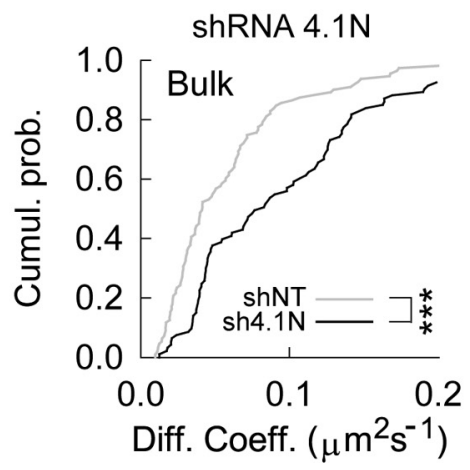

F

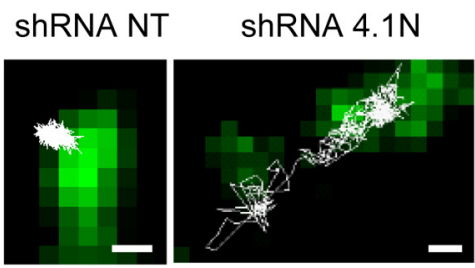

I

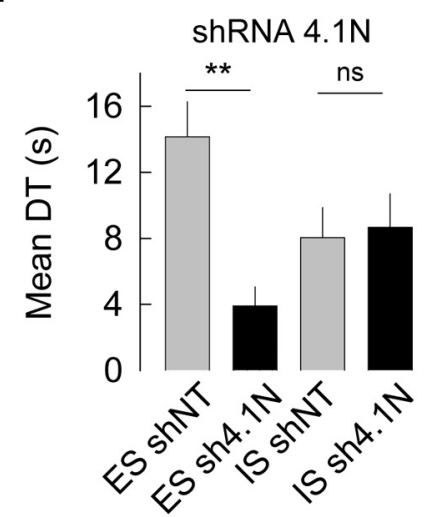

Figure 4. F-actin depolymerization and KCC2-actin binding interference increase the lateral diffusion of KCC2. A-C, Cumulative probability plots of diffusion coefficients (for bulk population of QDs) of KCC2-Flag in control conditions (gray in $\boldsymbol{A}$ ) or during application of latrunculin A (black in $\boldsymbol{A}$ ), in neurons transfected with eGFP (gray in $\boldsymbol{B}$ ), KCC2-CTD (black in $\boldsymbol{B}$ ), nontarget shRNA (gray in $\boldsymbol{C}$, and shRNA against 4.1N (black in $\boldsymbol{C}$. Note the increase $\left.{ }^{* * *} p<10^{-4}\right)$ in KCC2-Flag diffusion coefficients during actin depolymerization, KCC2-CTD overexpression, or 4.1N suppression. $\boldsymbol{D}-\boldsymbol{F}$, Examples of KCC2-Flag trajectories in control $\left(\boldsymbol{D} ; 827\right.$ frames, $\left.D=4 \times 10^{-2} \mu \mathrm{m}^{2} \mathrm{~s}^{-1}\right)$ versus latrunculin A application $\left(\boldsymbol{D} ; 944\right.$ frames, $\left.D=9 \times 10^{-2} \mu \mathrm{m}^{2} \mathrm{~s}{ }^{-1}\right)$, or in neurons transfected with $\operatorname{eGFP}\left(\boldsymbol{E} ; 974\right.$ frames, $\left.D=4 \times 10^{-2} \mu \mathrm{m}^{2} \mathrm{~s}^{-1}\right)$ versus KCC2-CTD $\left(\boldsymbol{E} ; 554\right.$ frames, $\left.D=9 \times 10^{-2} \mu \mathrm{m}^{2} \mathrm{~s}^{-1}\right)$, or in nontarget shRNA $\left(\boldsymbol{F} ; 494\right.$ frames, $\left.D=4 \times 10^{-2} \mu \mathrm{m}^{2} \mathrm{~s}^{-1}\right)$ versus $4.1 \mathrm{~N}$ shRNA $\left(F ; 380\right.$ frames, $\left.D=13 \times 10^{-2} \mu \mathrm{m}^{2} \mathrm{~s}^{-1}\right)$ expressing neurons. QD trajectories were overlaid with fluorescent clusters of recombinant homer1c-GFP (green) to identify excitatory synapses. Scale bars, $0.5 \mu \mathrm{m}$. Note the increase in surface exploration and faster escape of KCC2 from excitatory synapses (green). G-I, Significant reduction in KCC2-Flag DT at excitatory synapses (ES) but not at inhibitory synapses (IS) after actin depolymerization with latrunculin (IS, $p=0.9)$, reduced KCC2 actin binding with $\mathrm{KCC}-\mathrm{CTD}$ overexpression or $4.1 \mathrm{~N}$ suppression $\left(\boldsymbol{G}^{*}{ }^{* *} p=3 \times 10^{-3} ; \boldsymbol{H}^{* * * *} p<\right.$ $\left.10^{-4} ; \boldsymbol{I},{ }^{* *} p=1.2 \times 10^{-3}\right)$. Ctrl, Control; lat, latrunculin.

Table 2. Effects of F-actin depolymerization and interference with actin binding on KCC2 mobility at excitatory and inhibitory synapses

\begin{tabular}{|c|c|c|c|c|c|c|}
\hline \multirow[b]{2}{*}{ Location } & \multicolumn{6}{|l|}{ Condition } \\
\hline & Control & Latrunculin A & eGFP & CTD & NT shRNA & 4.1N shRNA \\
\hline $\begin{array}{l}\text { Bulk median } \\
\qquad D\left(10^{-2} \mu \mathrm{m}^{2} \mathrm{~s}^{-1}\right)\end{array}$ & $4.3(258,24,3)$ & $6.5(302,35,3)$ & $3.4(312,24,3)$ & $5.0(369,35,3)$ & $4.2(93,19,2)$ & $8.3(111,25,2)$ \\
\hline ES mean DT & $10.4 \pm 1.5(83,24,3)$ & $4.6 \pm 0.9(111,35,3)$ & $14.2 \pm 1.0(262,18,5)$ & $7.3 \pm 0.6(407,28,5)$ & $14.2 \pm 2.2(53,19,2)$ & $3.9 \pm 1.2(56,25,2)$ \\
\hline IS mean DT & $8.0 \pm 1.5(68,24,3)$ & $6.7 \pm 1.2(103,24,3)$ & $11.0 \pm 1.1(159,18,5)$ & $9.7 \pm 0.8(278,28,5)$ & $8.1 \pm 1.8(54,19,2)$ & $8.7 \pm 2.1(45,25,2)$ \\
\hline
\end{tabular}

Numbers in parentheses indicate the numbers of QDs, cells, and cultures analyzed. ES, QDs at excitatory synapses; IS, QDs at inhibitory synapses. Mean values are shown \pm SEM.

brated the probe in our system using a nigericin-tributyltin paradigm (see Materials end Methods; Krapf et al., 1988; Trapp et al., 1996; Marandi et al., 2002; Metzger et al., 2002). In agreement with previous work (Markova et al., 2008; Waseem et al., 2010), the CFP/YFP fluorescence ratio was tightly correlated with chlo- ride concentration with maximal sensitivity in the physiological $(10-100 \mathrm{~mm})$ range (Fig. 2A). COS cells were then transfected with the CFP-YFP probe alone or together with either wild-type (WT) or Flag-tagged KCC2 constructs (Fig. 2B,C). We observed a significant decrease in the CFP/YFP ratio in cells expressing 
A
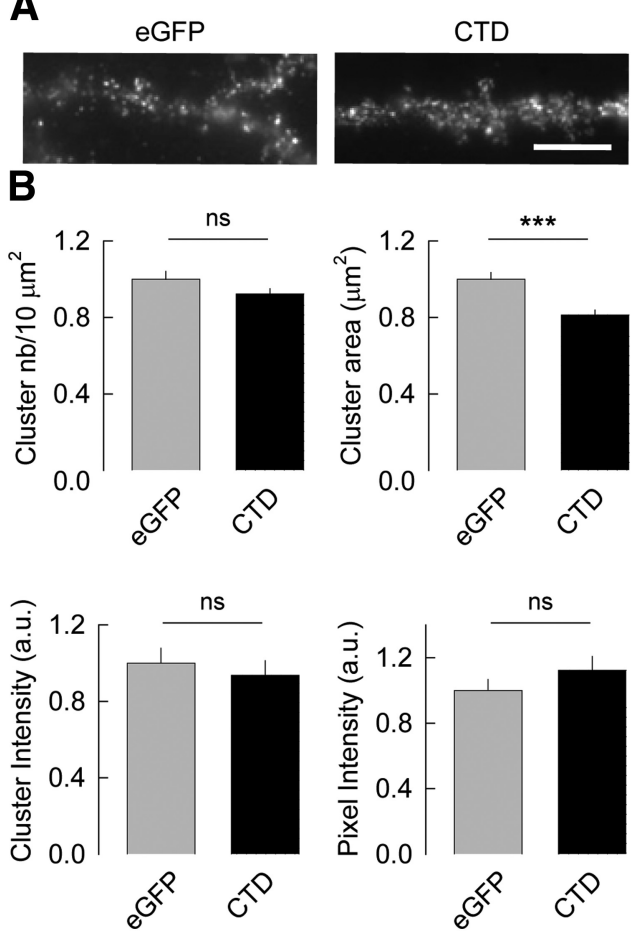

Figure 5. Effects of overexpression of the CTD of KCC2 on its clustering. A, KCC2-Flag remains clustered at the surface of hippocampal neurons after KCC2-CTD overexpression. Scale bar, $10 \mu \mathrm{m}$. $\boldsymbol{B}$, Summary plots of the effect of KCC2-CTD overexpression on the number of KCC2-Flag clusters per $10 \mu \mathrm{m}^{2}$, cluster size, mean fluorescence intensity per cluster, and mean fluorescence intensity per pixel within clusters. Values were normalized to the corresponding control values. eGFP, $n=36$; KCC2-CTD, $n=34$; three cultures; ${ }^{* * *} p<10^{-3}$.

either forms of KCC2 compared with cells transfected with the chloride probe alone $(\sim 15 \%$; Fig. $2 B, C)$. However, no significant difference was detected between cells expressing WT or Flagtagged KCC2 (Mann-Whitney test, $p=7 \times 10^{-2}$; Fig. 2B, C). These results demonstrate that Flag-tag insertion in the second predicted extracellular loop does not compromise KCC2 function, in agreement with previous work (Zhao et al., 2008; Acton et al., 2012).

We next asked whether expression of exogenous KCC2-Flag may increase KCC2 expression level and alter chloride extrusion properties in transfected neurons. We found that KCC2-Flag expression did not significantly increase the mean KCC2 fluorescence intensity (eGFP, $1.0 \pm 9.2 \times 10^{-2}, n=22$; KCC2-Flag plus eGFP, $1.3 \pm 14.0 \times 10^{-2}, n=25$; two cultures; $p=9.4 \times 10^{-2}$; data not shown). To compare KCC2 function in neurons expressing KCC2-Flag with cells expressing endogenous KCC2, we measured the somatodendritic gradient of $E_{\mathrm{GABA}}$ using local photolysis of caged GABA (Khirug et al., 2005; Gauvain et al., 2011). In neurons expressing KCC2-Flag and eGFP, we measured a gradient of $14.4 \pm 3.0 \mathrm{mV} / 100 \mu \mathrm{m}$ between somatic and dendritic $E_{\mathrm{GABA}}$ (Fig. $2 D-F$ ). This gradient was not significantly different in neurons transfected with eGFP alone $(14.1 \pm 1.6 \mathrm{mV} / 100 \mu \mathrm{M}$; Fig. $2 D-F)$. We conclude that exogenous expression of KCC2-Flag does not significantly increase expression and function of KCC2. Altogether, our data report that recombinant KCC2-Flag is a suitable tool to study cell and membrane trafficking of the transporter in neurons without perturbing neuronal chloride homeostasis.

\section{Constrained diffusion of KCC2 at glutamatergic and GABAergic synapses}

Neurons were cotransfected at 14 DIV with KCC2-Flag, homer1c-GFP, and gephyrin-mRFP, surface labeled at 22-25 DIV with Flag antibodies, and subsequently labeled with specific intermediate biotinylated Fab fragments and streptavidin-coated QDs (see Materials and Methods). The cell surface exploration of KCC2-Flag was analyzed from $36 \mathrm{~s}$ recording sequences. As shown in Figure $3 A$, surface exploration of QDs was restricted to smaller areas at synapses compared with extrasynaptic membranes. In some cases, QDs rapidly exchanged between extrasynaptic and synaptic compartments or escaped synaptic areas and further explored neighboring synapses (data not shown). Quantitative analysis performed on whole populations of trajectories confirmed reduced surface exploration of KCC2-Flag at excitatory and inhibitory synapses. MSD versus time plots showed a steeper slope for extrasynaptic trajectories (Fig. 3B), indicative of lower confinement. Accordingly, the mean size of the confinement domain $(L)$ was increased by $\sim 1$. 3 -fold in extrasynaptic membranes compared with synaptic membranes (Fig. 3C). Furthermore, synaptic QDs were significantly (0.8-fold) less mobile than extrasynaptic QDs, as detected from cumulative probability plots of diffusion coefficients and median diffusion coefficient $D$ values (Fig. $3 D, E$ ). Thus, KCC2-Flag shows reduced lateral mobility and increased diffusion constraints at excitatory and inhibitory synapses compared with extrasynaptic regions. However, diffusion coefficients and the size of confinement domains of KCC2-Flag were similar at both types of synapses (Fig. 3C,E). In contrast, the DT of KCC2-Flag was 1.3-fold longer at excitatory compared with inhibitory synapses (Fig. $3 F, G$ ), suggestive of a faster escape from inhibitory synapses. The median $D$ values, mean $L$, and DT values of KCC2 in the extrasynaptic membrane at excitatory or inhibitory synapses are summarized in Table 1. We conclude that KCC2-Flag undergoes stronger diffusion constraints at excitatory synapses compared with inhibitory synapses.

\section{Effects of altered KCC2-actin interactions on lateral} diffusion, clustering, and transport function of KCC2-Flag The intracellular CTD of KCC2 interacts with the actin cytoskeleton through the neuronal actin-linker protein $4.1 \mathrm{~N}$ ( $\mathrm{Li}$ et al., 2007). Such interaction may then hinder the lateral diffusion of KCC2 in the plasma membrane. Therefore, we examined the impact of KCC2-actin interactions on the lateral diffusion and clustering of KCC2. For this purpose, we induced F-actin depolymerization using latrunculin A (10 min at $5 \mu \mathrm{M}$; Allison et al., 2000), prevented KCC2 interaction with cytosolic partners by overexpressing its CTD (KCC2-CTD; Li et al., 2007; Gauvain et al., 2011), or specifically disrupted KCC2 interaction with $4.1 \mathrm{~N}$ using RNA interference against 4.1N (Lin et al., 2009). We then examined the impact of these manipulations on KCC2 membrane dynamics. Bulk diffusion of KCC2-Flag (i.e., independent of synaptic vs extrasynaptic localization) was increased by $\sim 1.5$ fold during actin depolymerization, KCC2-CTD overexpression, or $4.1 \mathrm{~N}$ suppression (Fig. $4 A-C$ ). In all three conditions, increased exploratory behavior of both extrasynaptic and synaptic trajectories was observed. However, facilitated synaptic escape of KCC2-Flag was specific of excitatory synapses (Fig. 4D-F). Consequently, KCC2-Flag DT at excitatory synapses was reduced by a 2.3-, 2.0-, and 3.6-fold during latrunculin treatment, KCC2CTD overexpression, or $4.1 \mathrm{~N}$ suppression (Fig. $4 G-I$ ). In contrast, none of these experimental conditions significantly altered KCC2 DT at inhibitory synapses (Fig. 4G-I). Median $D$ values for 
A

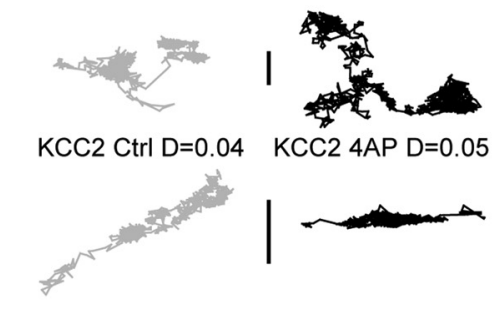

NCAM Ctrl D=0.09 NCAM 4AP D $=0.09$

D

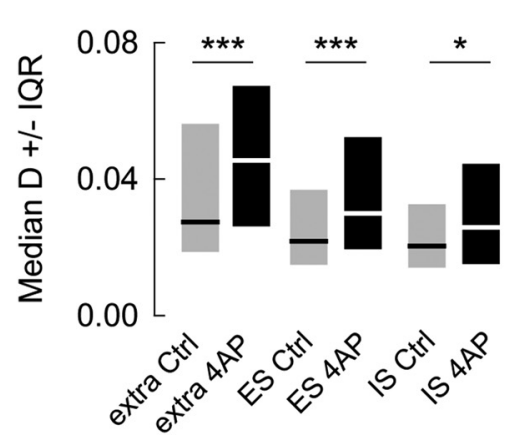

B

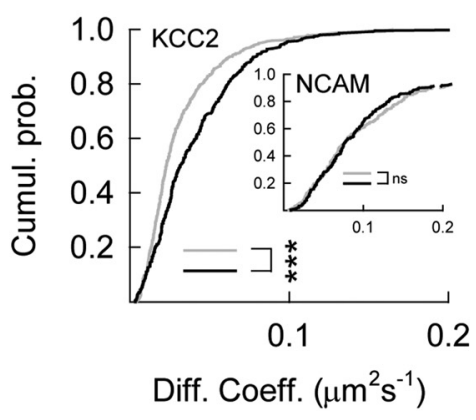

E

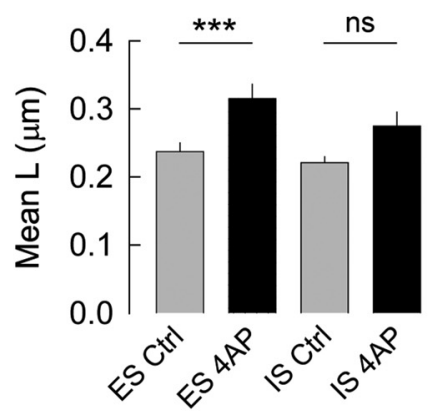

C

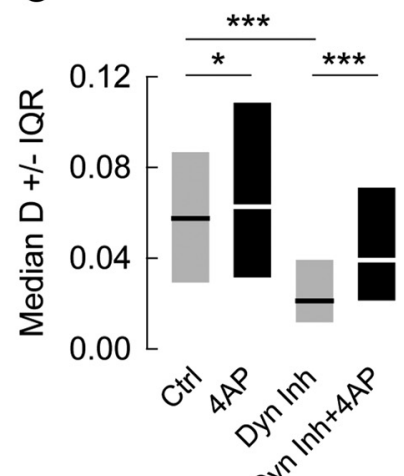

$\mathbf{F}$

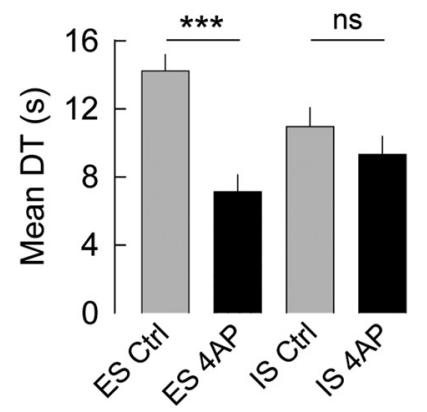

Figure 6. Elevated neuronal activity increases the membrane dynamics of KCC2 at excitatory synapses. $A$, Examples of trajectories of QD-coupled KCC2-Flag and NCAM-120 in the absence (1049 and 708 frames) or presence of 4-AP (1155 and 825 frames). Scale bar, $0.5 \mu \mathrm{m}$. B, Cumulative probabilities of diffusion coefficients (for bulk population of QDs) associated with KCC2-Flag (control, $n=507 ; 4-\mathrm{AP}, n=430,4$ cultures) or NCAM-120 (inset; control, $n=241 ; 4-\mathrm{AP}, n=228,2$ cultures) in the absence (gray) or presence (black) of 4-AP. Note the selective increase in KCC2 diffusion after 4-AP treatment $\left({ }^{* * *} p<10^{-3}\right)$. C, Median QD diffusion coefficient $D$ values $\pm 25-75 \%$ IQR (for bulk population of QDs) measured in the absence (left) or presence (right) of the membrane-permeant dynamin inhibitory peptide (dynamin inh) in control (gray) or 4-AP (black) conditions. Slowing down of KCC2 $\left(* * * p<10^{-4}\right.$ ) in the presence of endocytosis blocker in basal activity conditions. In the same culture, 4-AP increased KCC2 mobility in the absence $\left({ }^{*} p=3 \times 10^{-2}\right)$ or presence $\left({ }^{* * *} p<10^{-4}\right)$ of the dynamin inhibitory peptide. $\boldsymbol{D}-\boldsymbol{F}$, Median diffusion coefficients $\pm 25-75 \%$ IQR $(\boldsymbol{D})$, mean confinement domain $L(\boldsymbol{E})$, and mean DT $(\boldsymbol{F})$ of KCC2-Flag in the extrasynaptic region (extra), at excitatory (ES) or inhibitory (IS) synapses, in the absence (gray) or presence (black) of 4-AP. Acute 4-AP treatment increased KCC2 diffusion coefficients in all membrane compartments $\left({ }^{*} p=2 \times 10^{-2}\right.$; $\left.{ }^{* * *} p=5 \times 10^{-4}\right)$, whereas it selectively reduced confinement and DT at excitatory synapses $\left({ }^{* * *} p<10^{-3}\right)$. Ctrl, Control.

Table 3. Effects of 4-AP on KCC2 lateral diffusion parameters

\begin{tabular}{llll}
\hline Location & Median & & \\
& $D\left(10^{-2} \mu \mathrm{m}^{2} \mathrm{~s}^{-1}\right)$ & Mean $L(\mathrm{~nm})$ & Mean DT (s) \\
\hline Control & & & \\
$\quad$ ES & $2.2(193)$ & $237.4 \pm 12.7(212)$ & $14.2 \pm 1.0(262)$ \\
IS & $2.1(157)$ & $221.1 \pm 8.90(142)$ & $11.0 \pm 1.1(159)$ \\
$\quad$ Extra & $2.8(157)$ & n.d. & n.d. \\
4-AP $(100 \mu \mathrm{m}, 10 \mathrm{~min})$ & & & \\
ES & $3.0(160)$ & $315.3 \pm 20.80(144)$ & $7.2 \pm 0.6(141)$ \\
IS & $2.6(133)$ & $274.8 \pm 20.5(117)$ & $9.4 \pm 1.1(163)$ \\
Extra & $4.5(137)$ & n.d. & n.d. \\
\hline
\end{tabular}

Quantifications from 49 (control) and 36 (4-AP) cells and four independent experiments. Numbers in parentheses indicate the numbers of QDs analyzed. ES, QDs at excitatory synapses; IS, QDs at inhibitory synapses; Extra, QDs at extrasynaptic sites; n.d., not determined. Mean values are shown \pm SEM.

bulk population of QDs and mean synaptic DT values in control versus altered KCC2-actin interaction are reported in Table 2. These results highlight specific KCC2-actin binding properties at excitatory synapses.

Increased lateral mobility of transmembrane proteins is often correlated with decreased clustering (Triller and Choquet, 2008). Therefore, we examined whether preventing KCC2 interactions with intracellular partners using KCC2-CTD overexpression actually reduced KCC2 clustering in hippocampal neurons. In control conditions, KCC2-Flag formed numerous clusters along the dendrites of transfected neurons (Fig. 5A). Overexpression of KCC2-CTD did not affect the density of clusters on dendritic membranes (Fig. 5B). However, the size of the clusters was reduced by 1.6-fold (Fig. $5 B$ ) with no reduction in either the mean fluorescence intensity of KCC2-Flag clusters (Fig. 5B) or the mean fluorescence intensity per pixel within clusters (Fig. 5B), showing only moderate effect of KCC2-CTD overexpression on KCC2 clustering. Consistent with this conclusion, overexpression of KCC2-CTD did not affect $\mathrm{Cl}^{-}$transport function, as observed previously (Gauvain et al., 2011). The somatodendritic $E_{\mathrm{GABA}}$ gradient was not significantly different in neurons cotransfected with KCC2-CTD and KCC2-Flag $(14.8 \pm 2.0 \mathrm{mV} / 100 \mu \mathrm{M}$, $n=12)$ compared with KCC2-Flag alone $(14.7 \pm 2.8 \mathrm{mV} / 100$ $\mu \mathrm{M}, n=7, p=0.6$; data not shown). Thus, altering KCC2 interaction with intracellular partners releases diffusion constraints to KCC2 without compromising its clustering or function.

Increased diffusion and reduced clustering and transport function of KCC2 upon enhanced neuronal activity

KCC2 function is downregulated by neuronal activity (Kaila et al., 1997; Reid et al., 2001; Rivera et al., 2002, 2004; Woodin et al., 2003; Fiumelli et al., 2005; Wang et al., 2006b,c; Pathak et al., 2007; Wake et al., 2007; Kitamura et al., 2008; Li et al., 2008; Lee et al., 2011; Shimizu-Okabe et al., 2011). Whether this reflects reduced intrinsic transport function or reduced membrane expression of the transporter remains unclear. Therefore, we asked whether increased neuronal activity may induce an alteration of KCC2 membrane diffusion. We examined this issue by comparing the membrane dynamics of recombinant KCC2-Flag in the 
A
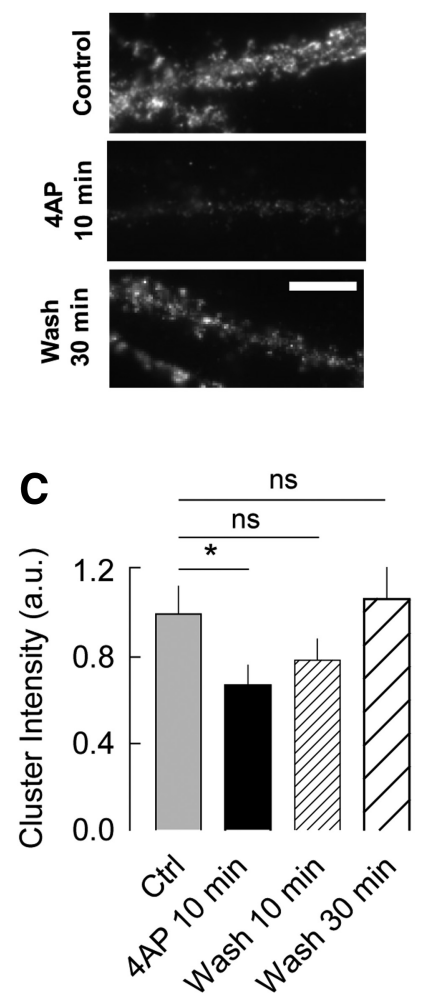

B
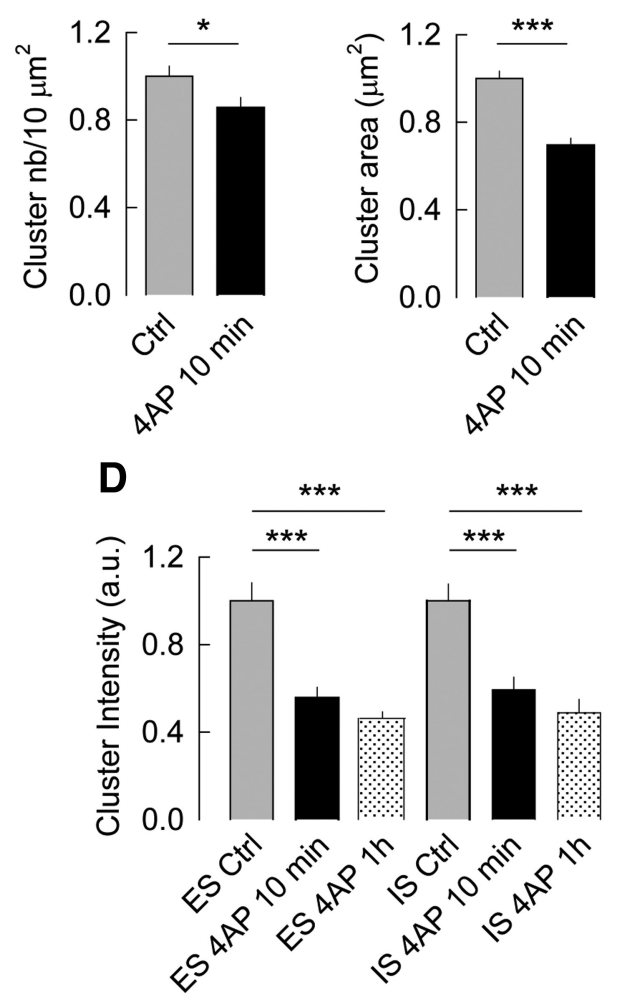
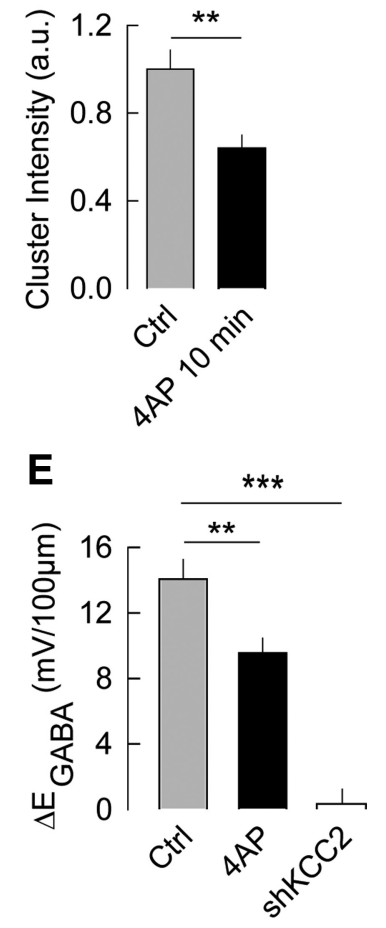

Figure 7. Increased neuronal activity disperses KCC2 clusters and reduces chloride export. $\boldsymbol{A}$, Flag surface staining in hippocampal neurons (23 DIV) expressing recombinant KCC2-Flag in the absence (Control) or presence of 4-AP for $10 \mathrm{~min}$ and after a $30 \mathrm{~min}$ washout (Wash). Scale bar, $10 \mu \mathrm{m}$. Note the loss of KCC2 clusters after 10 min exposure to 4 -AP and the recovery of clusters 30 min after drug washout. B, Quantifications showing significant reduction in the number of KCC2-Flag clusters per $10 \mu \mathrm{m}^{2}$ (left), cluster size (middle), and cluster intensity (right) after 10 min of 4-AP. Values were normalized to the corresponding control values. Control, $n=26 ; 4$-AP at 10 min, $n=31 ;$ three cultures; ${ }^{*} p=3 \times 10^{-2},{ }^{* *} p=2 \times 10^{-3},{ }^{* * *} p<10^{-3}$. C, The mean fluorescence intensity of KCC2-Flag clusters was reduced by $30 \%$ in neurons exposed for 10 min to 4-AP (black) compared with untreated cells (gray). The mean cluster intensity started to increase $10 \mathrm{~min}$ (fine hatched) after drug removal to return to control values $30 \mathrm{~min}$ (large hatched) later. Values were normalized to the corresponding control values. Control, $n=22 ; 4$-AP at 10 min, $n=$ 26; 4-AP washout at $10 \mathrm{~min}, n=25$; 4 -AP washout at $30 \mathrm{~min}, n=22$; two cultures; ${ }^{*} p=3 \times 10^{-2}$. D , Effect of 4-AP on the mean fluorescence intensity of KCC 2 aggregates at excitatory (ES) and inhibitory (IS) synapses showing dispersion of KCC2 clusters at either type of synapses after $10 \mathrm{~min}$ (black) or $1 \mathrm{~h}$ (black dots) exposure to $4-A P$ compared with control conditions (gray). Values were normalized to the corresponding control. Excitatory synapses: control, $n=38 ; 4-\mathrm{AP}$ at $10 \mathrm{~min}, n=31 ; 4-\mathrm{AP}$ at $1 \mathrm{~h}, n=31$; inhibitory synapses: control, $n=39 ; 4-\mathrm{AP}$ at 10 min, $n=31 ; 4-\mathrm{AP}$ at $1 \mathrm{~h}, n=32$; four cultures; ${ }^{* * *} p<10^{-3}$.E, 4-AP reduces the chloride ion transport capacity of treated neurons. Reduced somatodendritic $E_{\mathrm{GABA}}$ gradient in neurons exposed to 4 -AP (black) versus neurons maintained in control (gray) conditions (control, $14.0 \pm 1.2, n=12 ; 4-\mathrm{AP}, 9.5 \pm 0.9, n=16 ; t$ test, ${ }^{* *} p=5.0 \times 10^{-3}$ ). In comparison, KCC shRNA (white) reduced by $98 \%$ the somatodendritic $E_{\mathrm{GABA}}$ gradient $\left(0.3 \pm 0.9, n=5 ; t\right.$ test, $\left.{ }^{* * *} p<10^{-3}\right)$. Ctrl, Control.

absence or presence of the potassium channel blocker 4-AP (100 $\mu \mathrm{M}) .4$-AP treatment leads to a rapid and robust increase in synaptic activity that persists during the application of the drug with no major depolarization (Bouthour et al., 2011). We found that 4-AP increased the exploratory behavior (Fig. 6A) and diffusion coefficients of bulk KCC2-Flag populations (Fig. 6B). This effect was specific to KCC2 and did not reflect a reduced membrane viscosity because it was not associated with a significant change in the exploratory behavior (Fig. $6 \mathrm{~A}$ ) or lateral diffusion of the membrane-associated, cell adhesion molecule NCAM-120 (Fig. 6B).

KCC2 internalization and degradation participate in the rapid downregulation of chloride homeostasis by excitation (Lee et al., 2010, 2011). We then asked whether the activity-dependent regulation of KCC2 membrane dynamics was dependent on endocytosis. We examined the impact of 4-AP on the lateral mobility of recombinant KCC2-Flag while pharmacologically blocking endocytosis using bath application of myristoylated QVPSRPNRAP dynamin inhibitory peptide (Marks and McMahon, 1998). Under basal activity conditions, blockade of endocytosis significantly slowed down KCC2 (by 2.8-fold; Fig. 6C; see Table 4). This effect was accompanied by a significant (1.9-fold) increase in the mean fluorescence intensity of membrane KCC2-Flag clusters 20 min after blocking endocytosis (Mann-Whitney test, $p<5.0 \times$ $10^{-2}$; control, 18 cells; dynamin inhibitor, 17 cells, two cultures; data not shown). The enhanced KCC2 clustering during endocytosis blockade suggests the transporter undergoes a rapid turnover from the cell membrane at steady state, in agreement with published work (Rivera et al., 2004; Lee et al., 2007). Furthermore, our results also reveal a tight correlation between membrane dynamics, clustering, and withdrawal of the transporter. During blockade of dynamin-dependent endocytosis, the amount of surface KCC2 increased, leading to an increase in the clustering and confinement of the transporter. In these conditions, however, 4-AP was still able to increase KCC2 mobility (by 1.9-fold; Fig. 6C; see Table 4). Thus, activity-dependent regulation of KCC2 membrane dynamics does not depend on and actually precedes its endocytosis from plasma membrane.

We then analyzed the effects of 4-AP on the diffusion behavior of KCC2 at excitatory and inhibitory synapses. 4-AP application increased KCC2-Flag diffusion by 1.6-, 1.4-, and 1.4-fold in the extrasynaptic membrane, at excitatory synapses and inhibitory synapses, respectively (Fig. 6D). This 4-AP-induced increase in diffusion was associated with a 1.3 -fold decrease in KCC2 con- 
finement at excitatory synapses but not at inhibitory synapses (Fig. 6E). Consistent with these observations, 4-AP induced a (twofold) faster escape of KCC2-Flag from excitatory synapses than from inhibitory synapses (Fig. 6F). These data are summarized in Table 3. Thus, KCC2 shows lower confinement and faster escape from excitatory but not inhibitory synaptic domains during increased neuronal activity.

We next analyzed the impact of increased neuronal activity on the membrane clustering of KCC2. Application of 4-AP rapidly reduced the membraneassociated KCC2-Flag immunoreactivity (Fig. 7A). Indeed, a $10 \mathrm{~min}$ exposure to 4-AP reduced the mean number (by 0.9fold) of membrane-associated KCC2Flag clusters as well as the size (by 0.7 fold) and fluorescence intensity (by 0.6fold) of the remaining clusters compared with untreated cells (Fig. 7B). The dispersal of KCC2-Flag clusters was totally reversible within $30 \mathrm{~min}$ of 4 -AP washout (Fig. $7 A, C$ ). The effect of 4 -AP on KCC2 clustering was similar at both excitatory and inhibitory synapses (Fig. 7D). Application of 4-AP reduced by approximately twofold the mean fluorescence intensity of KCC2-Flag clusters at both excitatory and inhibitory synapses (Fig. $7 D)$. The effect of 4-AP on KCC2-Flag clusters was independent of a remodeling of the postsynaptic scaffold because the size of homer1c-GFP and gephyrin-mRFP clusters remained unchanged after $10 \mathrm{~min}$ or $1 \mathrm{~h}$ of 4 -AP (control, $n=25$; 4 -AP at $10 \mathrm{~min}, n=15$; 4 -AP at $1 \mathrm{~h}$, $n=21$; two cultures; 4 -AP at $10 \mathrm{~min}$ vs control, $p=0.8$ and 0.2 at excitatory and inhibitory synapses, respectively; 4 -AP at $1 \mathrm{~h}$ vs control, $p=0.1$ and 0.5 at excitatory and inhibitory synapses, respectively, Mann-Whitney test; data not shown). However, the loss of KCC2-Flag clusters was accompanied by an alteration of the transport function of KCC2. Indeed, the somatodendritic $E_{\mathrm{GABA}}$ gradient was reduced by $32 \%$ in neurons exposed to 4 -AP compared with control (Fig. 7E). In comparison, suppression of KCC2 expression by RNA interference reduced $E_{\mathrm{GABA}}$ somatodendritic gradient by 98\% (Fig. 7E), in agreement with our previous work (Gauvain et al., 2011). Therefore, we conclude that enhanced neuronal activity increases the lateral diffusion of $\mathrm{KCC} 2$, leading to reduced membrane clustering and chloride extrusion.

\section{Molecular mechanisms underlying the activity-dependent regulation of $\mathrm{KCC} 2$ diffusion and clustering}

To identify the molecular mechanisms involved in activityinduced increase of KCC2 diffusion, we compared the effects of 4 -AP in the presence or absence of the sodium channel blocker TTX ( $1 \mu \mathrm{M}$; Fig. 8A), the NMDAR antagonist AP-5 (100 $\mu \mathrm{M}$; Fig. $8 B)$, the $\mathrm{Ca}^{2+}$ chelator EGTA $(1.8 \mathrm{~mm}$; Fig. $8 \mathrm{C})$, the AMPAR antagonist NBQX $(10 \mu \mathrm{M}$; Fig. $8 D)$, or the group I/group II mGluR antagonist $R, S-\mathrm{MCPG}(500 \mu \mathrm{M}$; Fig. $8 E)$. TTX, AP-5, and EGTA completely abolished the effects of 4-AP on the diffusion of KCC2-Flag (Fig. 8A-C). In contrast, NBQX and $R, S-M C P G$ did not prevent 4-AP-induced acceleration of KCC2-Flag (Fig. $8 D, E)$. Furthermore, acute application of NMDA $(50 \mu \mathrm{M})$ increased the exploratory behavior and diffusion of KCC2 (Fig. $8 F$ ), showing that direct activation of NMDARs mimics the effect of 4-AP on KCC2 diffusion. These results demonstrate that 4-AP leads to an increased diffusion of KCC2 through action potentialdependent, synaptic activation of NMDARs and subsequent $\mathrm{Ca}^{2+}$ influx.

Interestingly, application of AP-5 alone reduced the diffusion of the recombinant transporter below that observed in control conditions (Fig. $8 F$ ), suggesting that NMDAR activation may regulate KCC2 mobility under basal activity. This effect of AP-5 was similar in the presence of high $(3 \mathrm{mM})$ or low $(1.5 \mathrm{~mm})$ extracellular $\left[\mathrm{Mg}^{2+}\right.$ ] (Fig. $8 F$ ). This suggests that, at steady state, NMDAR-dependent control of KCC2 diffusion may involve tonic activity of receptors with low $\mathrm{Mg}^{2+}$ sensitivity, possibly containing the NR2C and/or NR2D subunits (Feldmeyer and Cull-Candy, 1996). We conclude that NMDAR activation and subsequent $\mathrm{Ca}^{2+}$ influx release diffusion constraints to KCC2 diffusion both at steady state and during sustained neuronal activity.

Dephosphorylation of KCC2 serine residue at position 940 in the intracellular CTD of KCC2 (S940) is required for activitydependent calcium-induced downregulation of KCC2 membrane stability (Lee et al., 2011). Thus, we tested the involvement of this residue in the activity-induced regulation of KCC2 diffusion and clustering. We generated KCC2-Flag constructs with 
A
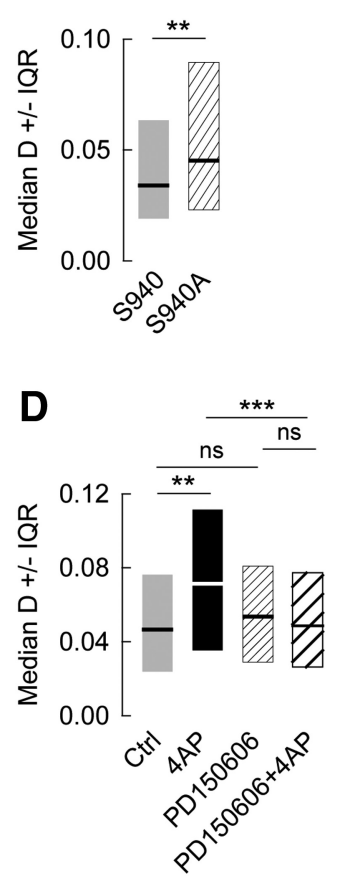

B
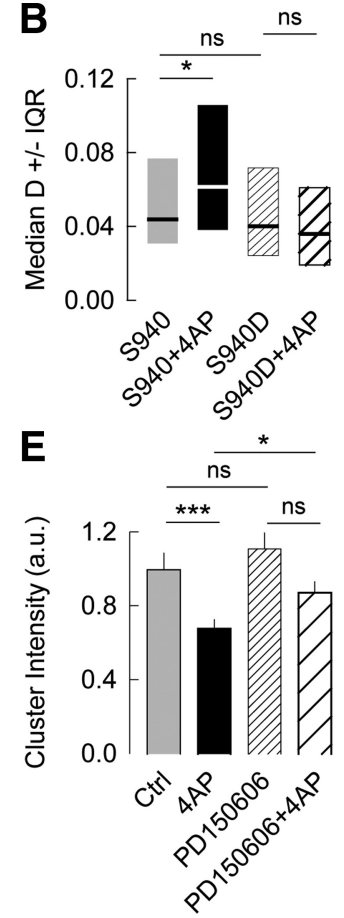

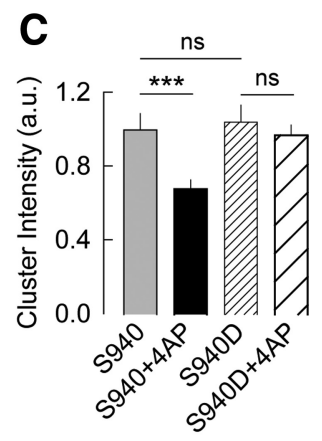

$\mathbf{F}$

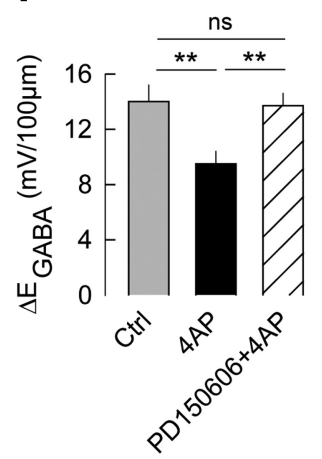

Figure 9. S940 dephosphorylation and calpain cleavage contribute to the 4-AP-mediated regulation of KCC2 diffusion, clustering, and function. $A-C$, Dephosphorylation of $S 940$ is required for activity-dependent regulation of KCC2 diffusion. $A$, Median QD diffusion coefficient $D$ values $\pm 25-75 \%$ IQR (for bulk population of QDs) of KCC2-S940 (gray) and KCC2-S940A (pattern) in basal activity conditions, showing increased mobility of the dephosphorylated KCC2-S940A transporter $\left({ }^{* *} p=2 \times 10^{-3}\right) . B, C$, Median QD diffusion coefficients values $\pm 25-75 \%$ IQR (for bulk population of QDs; $\boldsymbol{B}$ ) and mean cluster fluorescence intensity ( $($ ) of KCC2-S940 (plain) and phospho-mimetic KCC2-S940D (pattern) in the absence (gray and fine pattern) or presence (black and coarse pattern) of 4-AP. Comparable diffusion behavior and clustering of KCC2-S940D and KCC2-S940. Note that 4-AP selectively reduced diffusion constraints $\left({ }^{*} p=2 \times 10^{-2}\right)$ and clustering $\left({ }^{* * *} p<10^{-3}\right)$ of KCC2-S940 but not of KCC2-S940D. C, $\mathrm{KCC}-\mathrm{S} 940, n=32 ; \mathrm{KCC} 2-\mathrm{S940D}, n=30 ; \mathrm{KCC}-\mathrm{S} 940$ plus 4-AP, $n=31 ; \mathrm{KCC}-\mathrm{S} 940 \mathrm{D}$ plus 4-AP, $n=28$; three cultures. $\boldsymbol{D}-\boldsymbol{F}$, Median QD diffusion coefficient $D$ values $\pm 25-75 \%$ IQR (for bulk population of $Q D s ; D$ ), mean cluster fluorescence intensity $(\boldsymbol{E})$ of KCC2-Flag, and somatodendritic gradient of $E_{\mathrm{GABA}}(\boldsymbol{F})$ in the absence (plain) or presence (pattern) of the calpain protease inhibitor PD150606, in control (gray and fine pattern) versus 4-AP (black and large pattern) conditions. No effect of calpain activity blockade in basal activity conditions. The 4-AP-induced increase in $\mathrm{KCC} 2$ diffusion $\left(\boldsymbol{D}_{,}^{* *} p=2 \times 10^{-3}\right)$ and decrease in clustering $\left(\boldsymbol{E}_{i}\right.$ $\left.{ }^{* * *} p<10^{-3}\right)$ and function $\left(\boldsymbol{F}^{* *} p=5 \times 10^{-3}, t\right.$ test $)$ was reversed by calpain inhibitor $\left(\boldsymbol{D},{ }^{* * *} p<10^{-3} ; \boldsymbol{E}^{*} p=2 \times 10^{-2}\right.$; $\boldsymbol{F}_{,}{ }^{* *} p=6 \times 10^{-3}, t$ test). $\boldsymbol{E}$, Control, $n=32 ; \mathrm{PD} 150606, n=34 ; 4-\mathrm{AP} n=31 ; 4-\mathrm{AP}$ plus PD150606, $n=27$; three cultures. $\boldsymbol{F}$, Control, $n=12 ; 4-\mathrm{AP}, n=16 ; 4$-AP plus PD150606, $n=9$.

S940 residue mutated in either aspartate (S940D) or alanine (S940A) to mimic KCC2 S940 phosphorylated or dephosphorylated states, respectively. Under basal activity conditions, KCC2S940A was 1.4-fold faster than the WT recombinant transporter (Fig. 9A). In contrast, the mobility and clustering of the KCC2S940D transporter did not differ significantly from that of the WT KCC2-Flag (Fig. 9B,C). These results indicate that the majority of membrane KCC2 is phosphorylated on S940 under basal activity conditions, as suggested previously (Lee et al., 2011). However, S-to-D mutation on 940 residue prevented the 4-APinduced increase in KCC2 lateral diffusion for bulk population of QDs (Fig. 9B; Table 4), as well as for extrasynaptic and synaptic QDs (Table 5). Furthermore, expression of the KCC2-S940D transporter precluded the 4-AP-induced increase in KCC2 cluster dispersal (Fig. 9C). Thus, activity-dependent regulation of KCC2 diffusion and clustering involves dephosphorylation of its S940 residue.

KCC2-CTD cleavage by calcium-activated calpain protease has been shown to contribute to the downregulation of KCC2 activity (Puskarjov et al., 2012; Zhou et al., 2012). Neuronal exposure to the calpain inhibitor PD150606 did not significantly alter KCC2 lateral diffusion or clustering (Fig. $9 D, E$ ), indicating that

membrane-inserted KCC2 is not cleaved under basal activity conditions. However, calpain inhibition entirely blocked the activity-induced increase in KCC2-Flag diffusion, decreased in clustering, and reduced function (Fig. 9D-F). Tables 4 and 5 summarize the median $D$ values of QDs in the absence or presence of the various drugs and mutations that target the molecular mechanisms underlying the effect of 4-AP. Our results indicate that the relief in diffusion constraints and subsequent dispersal of KCC2 clusters during increased neuronal activity rely on protein cleavage by intracellular, calciumactivated calpain.

\section{Discussion}

In this study, we investigated the membrane dynamics and clustering of KCC2 under basal and sustained neuronal activity in hippocampal neurons. Our work demonstrates that KCC2 membrane expression can be rapidly regulated by synaptic activity through changes in lateral diffusion. KCC2 is enriched in the vicinity of both excitatory and inhibitory synapses. In resting conditions, KCC2 is more confined at synapses compared with extrasynaptic regions. Restriction of KCC2 diffusion at excitatory, but not inhibitory synapses relies on its tethering to the actin cytoskeleton via the adaptor protein $4.1 \mathrm{~N}$. However, this structural interaction with F-actin is not essential for KCC2 clustering per se, suggesting that other mechanisms may be at play to cluster KCC2 in neuronal membranes. Finally, NMDAR activation and subsequent $\mathrm{Ca}^{2+}$ influx rapidly increase KCC2 lateral diffusion presumably through S940 dephosphorylation and calpain-dependent cleavage of KCC2-CTD. This effect is correlated to a reversible dispersal of KCC2 membrane clusters and reduced chloride export. Thus, lateral diffusion and clustering of KCC2 are key mechanisms that rapidly and reversibly regulate KCC2 membrane expression and function through glutamate signaling.

Consistent with its synaptic aggregation, KCC2 diffusion was restricted in the vicinity of synapses compared with extrasynaptic regions. Importantly, KCC2 DT at excitatory synapses was longer than at inhibitory synapses, suggestive of different molecular constraints to the diffusion of KCC2 at these sites. KCC2 was shown to be involved in both the morphogenesis of dendritic spines (Li et al., 2007; Fiumelli et al., 2013) and the efficacy of glutamatergic transmission (Gauvain et al., 2011) through structural interactions with the actin cytoskeleton likely involving $4.1 \mathrm{~N}$. Therefore, we tested the hypothesis that restricted diffusion of KCC2 at excitatory synapses relies on its interaction with actin. Inhibition of F-actin polymerization using latrunculin A, overexpression of KCC2CTD as a dominant negative of its intracellular interactions, or knockdown of its intracellular partner 4.1N (Li et al., 2007) by RNA interference selectively induced the escape of KCC2 from 
Table 4. Molecular mechanisms underlying 4-AP-dependent regulation of KCC2 lateral diffusion

\begin{tabular}{lllll}
\hline & \multicolumn{4}{l}{ Median $D\left(10^{-2} \mu \mathrm{m}^{2} \mathrm{~s}^{-1}\right)$ for bulk population of QDs } \\
\cline { 2 - 5 } & Control & 4-AP & Drug/mutant & $\begin{array}{l}\text { Drug/mutant + } \\
\text { 4-AP }\end{array}$ \\
\hline $\begin{array}{l}\text { Dynamin } \\
\text { inhibitor }\end{array}$ & $5.8(202,14,2)$ & $6.3(249,10,2)$ & $2.1(193,10,2)$ & $3.9(200,7,2)$ \\
TTX & $4.6(318,26,3)$ & $6.3(303,21,3)$ & $5.1(324,14,3)$ & $4.8(230,16,3)$ \\
AP-5 & $2.9(391,29,3)$ & $4.0(325,24,3)$ & $2.3(322,17,3)$ & $2.2(344,20,3)$ \\
EGTA & $3.4(165,17,3)$ & $6.6(181,19,3)$ & $3.6(157,17,3)$ & $3.7(213,20,3)$ \\
NBQX & $3.6(366,31,4)$ & $4.4(360,24,4)$ & $3.2(220,22,4)$ & $4.1(335,18,4)$ \\
R,S-MCPG & $3.4(308,25,3)$ & $4.2(319,19,3)$ & $2.8(246,15,3)$ & $3.6(308,16,3)$ \\
S940A & $3.4(270,18,3)$ & n.d. & $4.6(234,14,3)$ & n.d. \\
S940D & $4.1(158,13,2)$ & $6.2(191,9,2)$ & $4.1(256,12,2)$ & $3.7(214,11,2)$ \\
PD150606 & $4.7(180,13,2)$ & $7.1(197,9,2)$ & $5.4(216,10,2)$ & $4.9(198,9,2)$ \\
\hline
\end{tabular}

Numbers in parentheses indicate the numbers of QDs, cells, and cultures analyzed. n.d., Not determined.

Table 5. The KCC2-S940D mutant and PD150606 calpain inhibitor prevented the 4-AP-induced increased mobility of synaptic and extrasynaptic KCC2-Flag transporters

\begin{tabular}{|c|c|c|c|c|c|c|}
\hline & \multicolumn{6}{|c|}{ Median $D\left(10^{-2} \mu \mathrm{m}^{2} \mathrm{~s}^{-1}\right)$} \\
\hline & \multicolumn{2}{|l|}{ Extra } & \multicolumn{2}{|l|}{ ES } & \multicolumn{2}{|l|}{ IS } \\
\hline & Ctrl & 4AP & Ctrl & $4 \mathrm{AP}$ & Ctrl & 4AP \\
\hline S940D & $4.1(176)$ & $4.1(190)$ & $2.9(68)$ & $2.3(81)$ & $2.8(98)$ & $2.3(78)$ \\
\hline PD150606 & $4.5(139)$ & $4.8(118)$ & 4.1 (72) & $3.4(44)$ & $3.6(85)$ & $2.7(53)$ \\
\hline
\end{tabular}

Numbers in parentheses indicate the numbers of QDs analyzed. The number of cells and cultures analyzed are as in Table 4. In all cases, there was no statistical significance between control and 4-AP conditions. Ctrl, Control; Extra, QDs at extrasynaptic sites; ES, QDs at excitatory synapses; IS, QDs at inhibitory synapses.

excitatory but not inhibitory synapses. Thus, KCC2 diffusion at excitatory and inhibitory synapses might not be hindered by the same intracellular interactions. F-actin is known to be enriched in dendritic spines but not on dendritic shafts in which inhibitory synapses are formed. Therefore, F-actin enrichment could account for the selective impact of cytoskeleton manipulations on KCC2 diffusion at excitatory synapses. The involvement of actin tethering on the hindering of KCC2 diffusion at excitatory synapses may have important implications regarding KCC2 function in dendritic spines. In a former study, we showed that KCC2 contributes to a diffusion barrier in dendritic spines through its structural interaction with the actin cytoskeleton, thereby restricting translocation of transmembrane proteins, including GluA1-containing AMPARs (Gauvain et al., 2011). Thus, release of actin-tethered KCC2 at excitatory synapses during enhanced neuronal activity could act to facilitate protein translocation in dendritic spines and thereby contribute to synaptic plasticity (Czöndör et al., 2012; Czöndör and Thoumine, 2013).

Increased lateral mobility of transmembrane proteins is often correlated with cluster dispersal (Bannai et al., 2009; Muir et al., 2010; Bouthour et al., 2011). Thus, we investigated whether the formation of KCC2 clusters was dependent on interactions of KCC2-CTD with intracellular partners by overexpressing this domain as a dominant negative. Surprisingly, KCC2 clusters were not dispersed during KCC2-CTD overexpression. This contrasts with the results obtained by Watanabe et al. (2009) showing reduced clustering of a KCC2 deletion mutant lacking the intracellular 1089-1116 sites. This discrepancy may be explained by differences in the methodology. Indeed, the experimental procedure used by Watanabe et al. did not permit to discriminate between cytoplasmic and membrane-inserted transporters, whereas we selectively stained the membrane pool of KCC2. We propose that deletion of the KCC2 1089-1116 sites may increase the intracellular pool of KCC2, thus hindering detection of membrane-inserted clusters. Lipid rafts are membrane microdomains enriched in cholesterol and sphingolipids (Simons and Toomre, 2000) and may participate in KCC2 clustering. Like the other CCC family members KCC3, KCC4 (Fujii et al., 2008), NKCC1, and $\mathrm{Na}^{+}-\mathrm{Cl}^{-}$cotransporter (Welker et al., 2008), KCC2 is associated with lipid rafts (Hartmann et al., 2009; Watanabe et al., 2009), and disruption of those by cholesterol depletion disperses KCC2 clusters in cultured hippocampal neurons (Watanabe et al., 2009). Thus, KCC2 clustering per se does not seem to rely on its interaction with the actin cytoskeleton, but subcellular localization of KCC2-containing rafts might depend on actin tethering through KCC2-CTD. Similarly to the serotonin transporter (Chang et al., 2012), KCC2 may remain confined to membrane rafts after relaxation of actin-associated molecular constraints. Actin-untethering may then relieve diffusion constraints onto KCC2-containing lipid rafts. KCC2 clustering may also involve an oligomerization process. KCC2 is known to multimerize into dimers, trimers, or tetramers (Blaesse et al., 2006; Simard et al., 2007; Uvarov et al., 2009). Preventing phosphorylation of Y1087 residue disrupts oligomerization and clustering of KCC2, suggesting a tight link between these two mechanisms (Watanabe et al., 2009). Thus, one or several molecular mechanisms may be at play to contribute to KCC2 aggregation. Our findings of different diffusion constraints of KCC2 at excitatory versus inhibitory synapses further support this hypothesis.

KCC2 clustering may serve to localize and concentrate the transporter to membrane subdomains, such as excitatory or inhibitory synapses. Clustering may also represent a mechanism for rapid alteration of KCC2 function. In fact, KCC2 dispersal after disruption of membrane rafts is correlated with a loss of function in hippocampal neurons (Watanabe et al., 2009), whereas aggregation in cholesterol-enriched membrane rafts upregulates KCC2 function. In our experiments, however, overexpression of the CTD of KCC2 did not alter KCC2 transport function, suggesting that aggregation but not actin tethering of KCC2 may be essential for its function.

Our results suggest that a transient increase in synaptic activity may then permit a rapid and local regulation of KCC2 diffusion/clustering and therefore function at excitatory and/or inhibitory synapses. Rapid activity-induced dephosphorylation of S940 and phosphorylation of Y903/1087 leads to reduced membrane stability of KCC2 through increased endocytosis and targeting to lysosomal degradation (Lee et al., 2010, 2011). KCC2-CTD cleavage by calcium-activated calpain protease also contributes to the downregulation of KCC2 activity (Puskarjov et al., 2012; Zhou et al., 2012). We showed that increasing neuronal activity-leading to NMDAR activation and subsequent $\mathrm{Ca}^{2+}$ influx, dephosphorylation of KCC2 S940, and calpain cleavage of its CTD-rapidly increases the lateral mobility of KCC2 while reducing its clustering and chloride export activity in neurons. Interestingly, the effect of increased activity on KCC2 diffusion was prevented by either calpain inhibitor or expression of phospho-mimetic KCC2S940D mutant. Because S940 is located on the C-terminal tail of the transporter, which is cleaved by calpain, we propose that dephosphorylation of S940 may be a prerequisite for calpain cleavage of membrane-associated transporter and lead to KCC2 endocytosis and subsequent recycling or degradation. Activity-induced reduction of clustering may then be an inter- 
mediate mechanism affecting KCC2 function. Increased neuronal activity leading to changes in KCC2 phosphorylation states may lead to a dispersion of the clusters and freely moving transporters may then become available for internalization and lysosomal degradation.

NMDAR-induced increase in KCC2 lateral mobility and cluster dispersal may have important implications for the efficacy of GABA signaling. The rapid, activity-dependent disruption of KCC2 diffusion and clustering impacts GABAergic transmission through reduced extrusion of chloride ions. This regulation, together with the NMDAR-dependent increase in $\mathrm{GABA}_{\mathrm{A}} \mathrm{R}$ diffusion and cluster dispersal (Bannai et al., 2009; Muir et al., 2010; Niwa et al., 2012), may then act to decrease the efficacy of GABAergic synapses and in turn facilitate longterm potentiation of excitatory synapses. Furthermore, KCC2 function is reduced under pathological conditions associated with enhanced neuronal activity, thereby contributing to an altered balance of excitation to inhibition that may contribute to excitotoxicity or anomalous synchronous activities underlying seizures (Reid et al., 2001; Rivera et al., 2002, 2004; Huberfeld et al., 2007; Pathak et al., 2007; Wake et al., 2007; Li et al., 2008; Shimizu-Okabe et al., 2011). Activity-driven dispersal of KCC2 clusters may then be one of the first molecular mechanisms favoring the emergence of these anomalous activities. Thus, favoring the membrane stability of KCC2 clusters might provide a new therapeutic strategy for the prevention of several neurological disorders, such as epilepsy, neuropathic pain, and posttraumatic spasticity.

\section{References}

Acton BA, Mahadevan V, Mercado A, Uvarov P, Ding Y, Pressey J, Airaksinen MS, Mount DB, Woodin MA (2012) Hyperpolarizing GABAergic transmission requires the KCC2 C-terminal ISO domain. J Neurosci 32:87468751. CrossRef Medline

Alivisatos AP, Gu W, Larabell C (2005) Quantum dots as cellular probes. Annu Rev Biomed Eng 7:55-76. CrossRef Medline

Allison DW, Chervin AS, Gelfand VI, Craig AM (2000) Postsynaptic scaffolds of excitatory and inhibitory synapses in hippocampal neurons: maintenance of core components independent of actin filaments and microtubules. J Neurosci 20:4545-4554. Medline

Báldi R, Varga C, Tamás G (2010) Differential distribution of KCC2 along the axo-somato-dendritic axis of hippocampal principal cells. Eur J Neurosci 32:1319-1325. CrossRef Medline

Bannai H, Lévi S, Schweizer C, Dahan M, Triller A (2006) Imaging the lateral diffusion of membrane molecules with quantum dots. Nat Protoc 1:2628-2634. CrossRef Medline

Bannai H, Lévi S, Schweizer C, Inoue T, Launey T, Racine V, Sibarita JB, Mikoshiba K, Triller A (2009) Activity-dependent tuning of inhibitory neurotransmission based on GABAAR diffusion dynamics. Neuron 62: 670-682. CrossRef Medline

Barthó P, Payne JA, Freund TF, Acsády L (2004) Differential distribution of the $\mathrm{KCl}$ cotransporter KCC2 in thalamic relay and reticular nuclei. Eur J Neurosci 20:965-975. CrossRef Medline

Bartho P, Curto C, Luczak A, Marguet SL, Harris KD (2009) Population coding of tone stimuli in auditory cortex: dynamic rate vector analysis. Eur J Neurosci 30:1767-1778. CrossRef Medline

Bats C, Groc L, Choquet D (2007) The interaction between Stargazin and PSD-95 regulates AMPA receptor surface trafficking. Neuron 53:719-734. CrossRef Medline

Belenky MA, Yarom Y, Pickard GE (2008) Heterogeneous expression of gamma-aminobutyric acid and gamma-aminobutyric acid-associated receptors and transporters in the rat suprachiasmatic nucleus. J Comp Neurol 506:708-732. CrossRef Medline

Blaesse P, Guillemin I, Schindler J, Schweizer M, Delpire E, Khiroug L, Friauf E, Nothwang HG (2006) Oligomerization of KCC2 correlates with development of inhibitory neurotransmission. J Neurosci 26:10407-10419. CrossRef Medline

Bonneau S, Dahan M, Cohen LD (2005) Single quantum dot tracking based on perceptual grouping using minimal paths in a spatiotemporal volume. IEEE Trans Image Process 14:1384-1395. CrossRef Medline

Bouthour W, Leroy F, Emmanuelli C, Carnaud M, Dahan M, Poncer JC, Lévi S (2012) A human mutation in Gabrg2 associated with generalized epilepsy alters the membrane dynamics of GABAA receptors. Cereb Cortex 22:1542-1553. CrossRef Medline

Chamma I, Chevy Q, Poncer JC, Lévi S (2012) Role of the neuronal K-Cl co-transporter KCC2 in inhibitory and excitatory neurotransmission. Front Cell Neurosci 6:5. CrossRef Medline

Chang JC, Tomlinson ID, Warnement MR, Ustione A, Carneiro AM, Piston DW, Blakely RD, Rosenthal SJ (2012) Single molecule analysis of serotonin transporter regulation using antagonist-conjugated quantum dots reveals restricted, p38 MAPK-dependent mobilization underlying uptake activation. J Neurosci 32:8919-8929. CrossRef Medline

Charrier C, Ehrensperger MV, Dahan M, Lévi S, Triller A (2006) Cytoskeleton regulation of glycine receptor number at synapses and diffusion in the plasma membrane. J Neurosci 26:8502-8511. CrossRef Medline

Czöndör K, Mondin M, Garcia M, Heine M, Frischknecht R, Choquet D, Sibarita JB, Thoumine OR (2012) Unified quantitative model of AMPA receptor trafficking at synapses. Proc Natl Acad Sci U S A 109:3522-3527. CrossRef Medline

Czöndör K, Thoumine O (2013) Biophysical mechanisms regulating AMPA receptor accumulation at synapses. Brain Res Bull 93:57-68. CrossRef Medline

Dahan M, Lévi S, Luccardini C, Rostaing P, Riveau B, Triller A (2003) Diffusion dynamics of glycine receptors revealed by single-quantum dot tracking. Science 302:442-445. CrossRef Medline

Ehrensperger MV, Hanus C, Vannier C, Triller A, Dahan M (2007) Multiple association states between glycine receptors and gephyrin identified by SPT analysis. Biophys J 92:3706-3718. CrossRef Medline

Feldmeyer D, Cull-Candy S (1996) Functional consequences of changes in NMDA receptor subunit expression during development. J Neurocytol 25:857-867. CrossRef Medline

Fiumelli H, Cancedda L, Poo MM (2005) Modulation of GABAergic transmission by activity via postsynaptic $\mathrm{Ca}^{2+}$-dependent regulation of $\mathrm{KCC} 2$ function. Neuron 48:773-786. CrossRef Medline

Fiumelli H, Briner A, Puskarjov M, Blaesse P, Belem BJ, Dayer AG, Kaila K, Martin JL, Vutskits L (2013) An ion transport-independent role for the cation-chloride cotransporter KCC2 in dendritic spinogenesis in vivo. Cereb Cortex 23:378-388. CrossRef Medline

Fujii T, Takahashi Y, Itomi Y, Fujita K, Morii M, Tabuchi Y, Asano S, Tsukada $\mathrm{K}$, Takeguchi N, Sakai H (2008) $\mathrm{K}^{+}-\mathrm{Cl}^{-}$cotransporter-3a up-regulates $\mathrm{Na}^{+}, \mathrm{K}^{+}$-ATPase in lipid rafts of gastric luminal parietal cells. J Biol Chem 283:6869-6877. CrossRef Medline

Gauvain G, Chamma I, Chevy Q, Cabezas C, Irinopoulou T, Bodrug N, Carnaud M, Lévi S, Poncer JC (2011) The neuronal K-Cl cotransporter KCC2 influences postsynaptic AMPA receptor content and lateral diffusion in dendritic spines. Proc Natl Acad Sci U S A 108:15474-15479. CrossRef Medline

Goslin K, Asmussen H, Banker G (1998) Rat hippocampal neurons in lowdensity culture. Cambridge, MA: Massachusetts Institute of Technology.

Gulyás AI, Sík A, Payne JA, Kaila K, Freund TF (2001) The KCl cotransporter, $\mathrm{KCC} 2$, is highly expressed in the vicinity of excitatory synapses in the rat hippocampus. Eur J Neurosci 13:2205-2217. CrossRef Medline

Hanus C, Ehrensperger MV, Triller A (2006) Activity-dependent movements of postsynaptic scaffolds at inhibitory synapses. J Neurosci 26:4586-4595. CrossRef Medline

Hartmann AM, Blaesse P, Kranz T, Wenz M, Schindler J, Kaila K, Friauf E, Nothwang HG (2009) Opposite effect of membrane raft perturbation on transport activity of KCC2 and NKCC1. J Neurochem 111:321-331. CrossRef Medline

Huberfeld G, Wittner L, Clemenceau S, Baulac M, Kaila K, Miles R, Rivera C (2007) Perturbed chloride homeostasis and GABAergic signaling in human temporal lobe epilepsy. J Neurosci 27:9866-9873. CrossRef Medline

Hübner CA, Stein V, Hermans-Borgmeyer I, Meyer T, Ballanyi K, Jentsch TJ (2001) Disruption of KCC2 reveals an essential role of K-Cl cotransport already in early synaptic inhibition. Neuron 30:515-524. CrossRef Medline

Kaila K, Lamsa K, Smirnov S, Taira T, Voipio J (1997) Long-lasting GABAmediated depolarization evoked by high-frequency stimulation in pyramidal neurons of rat hippocampal slice is attributable to a network- 
driven, bicarbonate-dependent $\mathrm{K}^{+}$transient. J Neurosci 17:7662-7672. Medline

Khirug S, Huttu K, Ludwig A, Smirnov S, Voipio J, Rivera C, Kaila K, Khiroug L (2005) Distinct properties of functional KCC2 expression in immature mouse hippocampal neurons in culture and in acute slices. Eur J Neurosci 21:899-904. CrossRef Medline

Kitamura A, Ishibashi H, Watanabe M, Takatsuru Y, Brodwick M, Nabekura J (2008) Sustained depolarizing shift of the GABA reversal potential by glutamate receptor activation in hippocampal neurons. Neurosci Res 62: 270-277. CrossRef Medline

Krapf R, Berry CA, Verkman AS (1988) Estimation of intracellular chloride activity in isolated perfused rabbit proximal convoluted tubules using a fluorescent indicator. Biophys J 53:955-962. CrossRef Medline

Kusumi A, Sako Y, Yamamoto M (1993) Confined lateral diffusion of membrane receptors as studied by single particle tracking (nanovid microscopy). Effects of calcium-induced differentiation in cultured epithelial cells. Biophys J 65:2021-2040. CrossRef Medline

Lee HH, Walker JA, Williams JR, Goodier RJ, Payne JA, Moss SJ (2007) Direct protein kinase C-dependent phosphorylation regulates the cell surface stability and activity of the potassium chloride cotransporter KCC2. J Biol Chem 282:29777-29784. CrossRef Medline

Lee HH, Jurd R, Moss SJ (2010) Tyrosine phosphorylation regulates the membrane trafficking of the potassium chloride co-transporter KCC2. Mol Cell Neurosci 45:173-179. CrossRef Medline

Lee HH, Deeb TZ, Walker JA, Davies PA, Moss SJ (2011) NMDA receptor activity downregulates KCC2 resulting in depolarizing GABA(A) receptor-mediated currents. Nat Neurosci 14:736-743. CrossRef Medline

Li H, Tornberg J, Kaila K, Airaksinen MS, Rivera C (2002) Patterns of cation-chloride cotransporter expression during embryonic rodent CNS development. Eur J Neurosci 16:2358-2370. CrossRef Medline

Li H, Khirug S, Cai C, Ludwig A, Blaesse P, Kolikova J, Afzalov R, Coleman SK, Lauri S, Airaksinen MS, Keinänen K, Khiroug L, Saarma M, Kaila K, Rivera C (2007) KCC2 interacts with the dendritic cytoskeleton to promote spine development. Neuron 56:1019-1033. CrossRef Medline

Li X, Zhou J, Chen Z, Chen S, Zhu F, Zhou L (2008) Long-term expressional changes of $\mathrm{Na}^{+}-\mathrm{K}^{+}-\mathrm{Cl}^{-}$co-transporter 1 (NKCC1) and $\mathrm{K}^{+}-\mathrm{Cl}^{-}{ }^{-} \mathrm{CO}-$ transporter 2 (KCC2) in CA1 region of hippocampus following lithiumpilocarpine induced status epilepticus (PISE). Brain Res 1221:141-146. CrossRef Medline

Lin DT, Makino Y, Sharma K, Hayashi T, Neve R, Takamiya K, Huganir RL (2009) Regulation of AMPA receptor extrasynaptic insertion by $4.1 \mathrm{~N}$, phosphorylation and palmitoylation. Nat Neurosci 12:879-887. CrossRef Medline

Marandi N, Konnerth A, Garaschuk O (2002) Two-photon chloride imaging in neurons of brain slices. Pflugers Arch 445:357-365. CrossRef Medline

Markova O, Mukhtarov M, Real E, Jacob Y, Bregestovski P (2008) Genetically encoded chloride indicator with improved sensitivity. J Neurosci Methods 170:67-76. CrossRef Medline

Marks B, McMahon HT (1998) Calcium triggers calcineurin-dependent synaptic vesicle recycling in mammalian nerve terminals. Curr Biol 8:740-749. CrossRef Medline

Metzger F, Repunte-Canonigo V, Matsushita S, Akemann W, Diez-Garcia J, Ho CS, Iwasato T, Grandes P, Itohara S, Joho RH, Knöpfel T (2002) Transgenic mice expressing a $\mathrm{pH}$ and $\mathrm{Cl}^{-}$sensing yellow-fluorescent protein under the control of a potassium channel promoter. Eur J Neurosci 15:40-50. CrossRef Medline

Muir J, Arancibia-Carcamo IL, MacAskill AF, Smith KR, Griffin LD, Kittler JT (2010) NMDA receptors regulate GABAA receptor lateral mobility and clustering at inhibitory synapses through serine 327 on the gamma2 subunit. Proc Natl Acad Sci U S A 107:16679-16684. CrossRef Medline

Niwa F, Bannai H, Arizono M, Fukatsu K, Triller A, Mikoshiba K (2012) Gephyrin-independent GABA(A)R mobility and clustering during plasticity. PLoS One 7:e36148. CrossRef Medline

Pathak HR, Weissinger F, Terunuma M, Carlson GC, Hsu FC, Moss SJ, Coulter DA (2007) Disrupted dentate granule cell chloride regulation enhances synaptic excitability during development of temporal lobe epilepsy. J Neurosci 27:14012-14022. CrossRef Medline

Puskarjov M, Ahmad F, Kaila K, Blaesse P (2012) Activity-dependent cleavage of the $\mathrm{K}-\mathrm{Cl}$ cotransporter $\mathrm{KCC} 2$ mediated by calcium-activated protease calpain. J Neurosci 32:11356-11364. CrossRef Medline

Reid KH, Li GY, Payne RS, Schurr A, Cooper NG (2001) The mRNA level of the potassium-chloride cotransporter KCC2 covaries with seizure susceptibility in inferior colliculus of the post-ischemic audiogenic seizureprone rat. Neurosci Lett 308:29-32. CrossRef Medline

Rivera C, Voipio J, Payne JA, Ruusuvuori E, Lahtinen H, Lamsa K, Pirvola U, Saarma M, Kaila K (1999) The $\mathrm{K}^{+} / \mathrm{Cl}^{-}$co-transporter KCC2 renders GABA hyperpolarizing during neuronal maturation. Nature 397: 251-255. CrossRef Medline

Rivera C, Li H, Thomas-Crusells J, Lahtinen H, Viitanen T, Nanobashvili A, Kokaia Z, Airaksinen MS, Voipio J, Kaila K, Saarma M (2002) BDNFinduced TrkB activation down-regulates the $\mathrm{K}^{+}-\mathrm{Cl}^{-}$cotransporter KCC2 and impairs neuronal $\mathrm{Cl}^{-}$extrusion. J Cell Biol 159:747-752. CrossRef Medline

Rivera C, Voipio J, Thomas-Crusells J, Li H, Emri Z, Sipilä S, Payne JA, Minichiello L, Saarma M, Kaila K (2004) Mechanism of activitydependent downregulation of the neuron-specific $\mathrm{K}-\mathrm{Cl}$ cotransporter KCC2. J Neurosci 24:4683-4691. CrossRef Medline

Saxton MJ, Jacobson K (1997) Single-particle tracking: applications to membrane dynamics. Annu Rev Biophys Biomol Struct 26:373-399. CrossRef Medline

Shimizu-Okabe C, Tanaka M, Matsuda K, Mihara T, Okabe A, Sato K, Inoue Y, Fujiwara T, Yagi K, Fukuda A (2011) KCC2 was downregulated in small neurons localized in epileptogenic human focal cortical dysplasia. Epilepsy Res 93:177-184. CrossRef Medline

Simard CF, Bergeron MJ, Frenette-Cotton R, Carpentier GA, Pelchat ME, Caron L, Isenring P (2007) Homooligomeric and heterooligomeric associations between $\mathrm{K}^{+}-\mathrm{Cl}^{-}$cotransporter isoforms and between $\mathrm{K}^{+}$$\mathrm{Cl}^{-}$and $\mathrm{Na}^{+}-\mathrm{K}^{+}-\mathrm{Cl}^{-}$cotransporters. J Biol Chem 282:18083-18093. CrossRef Medline

Simons K, Toomre D (2000) Lipid rafts and signal transduction. Nat Rev Mol Cell Biol 1:31-39. CrossRef Medline

Szabadics J, Varga C, Molnár G, Oláh S, Barzó P, Tamás G (2006) Excitatory effect of GABAergic axo-axonic cells in cortical microcircuits. Science 311:233-235. CrossRef Medline

Takayama C, Inoue Y (2006) Developmental localization of potassium chloride co-transporter 2 in granule cells of the early postnatal mouse cerebellum with special reference to the synapse formation. Neuroscience 143:757-767. CrossRef Medline

Trapp S, Lückermann M, Brooks PA, Ballanyi K (1996) Acidosis of rat dorsal vagal neurons in situ during spontaneous and evoked activity. J Physiol 496:695-710. Medline

Triller A, Choquet D (2008) New concepts in synaptic biology derived from single-molecule imaging. Neuron 59:359-374. CrossRef Medline

Uvarov P, Ludwig A, Markkanen M, Soni S, Hübner CA, Rivera C, Airaksinen MS (2009) Coexpression and heteromerization of two neuronal K-Cl cotransporter isoforms in neonatal brain. J Biol Chem 284:13696-13704. CrossRef Medline

Vale C, Caminos E, Martinez-Galán JR, Juiz JM (2005) Expression and developmental regulation of the $\mathrm{K}^{+}-\mathrm{Cl}^{-}$cotransporter $\mathrm{KCC} 2$ in the cochlear nucleus. Hear Res 206:107-115. CrossRef Medline

Vanhatalo S, Palva JM, Andersson S, Rivera C, Voipio J, Kaila K (2005) Slow endogenous activity transients and developmental expression of $\mathrm{K}^{+}-\mathrm{Cl}^{-}$ cotransporter 2 in the immature human cortex. Eur J Neurosci 22:27992804. CrossRef Medline

Vinay L, Jean-Xavier C (2008) Plasticity of spinal cord locomotor networks and contribution of cation-chloride cotransporters. Brain Res Rev 57: 103-110. CrossRef Medline

Wake H, Watanabe M, Moorhouse AJ, Kanematsu T, Horibe S, Matsukawa N, Asai K, Ojika K, Hirata M, Nabekura J (2007) Early changes in KCC2 phosphorylation in response to neuronal stress result in functional downregulation. J Neurosci 27:1642-1650. CrossRef Medline

Wang L, Kitai ST, Xiang Z (2006a) Activity-dependent bidirectional modification of inhibitory synaptic transmission in rat subthalamic neurons. J Neurosci 26:7321-7327. CrossRef Medline

Wang W, Gong N, Xu TL (2006b) Downregulation of KCC2 following LTP contributes to EPSP-spike potentiation in rat hippocampus. Biochem Biophys Res Commun 343:1209-1215. CrossRef Medline

Wang W, Wang H, Gong N, Xu TL (2006c) Changes of $\mathrm{K}^{+}-\mathrm{Cl}^{-}$cotransporter 2 (KCC2) and circuit activity in propofol-induced impairment of long-term potentiation in rat hippocampal slices. Brain Res Bull 70:444449. CrossRef Medline

Waseem T, Mukhtarov M, Buldakova S, Medina I, Bregestovski P (2010) Genetically encoded $\mathrm{Cl}$-Sensor as a tool for monitoring of $\mathrm{Cl}$-dependent pro- 
cesses in small neuronal compartments. J Neurosci Methods 193:14-23. CrossRef Medline

Watanabe M, Wake H, Moorhouse AJ, Nabekura J (2009) Clustering of neuronal $\mathrm{K}^{+}-\mathrm{Cl}^{-}$cotransporters in lipid rafts by tyrosine phosphorylation. J Biol Chem 284:27980-27988. CrossRef Medline

Welker P, Böhlick A, Mutig K, Salanova M, Kahl T, Schlüter H, Blottner D, Ponce-Coria J, Gamba G, Bachmann S (2008) Renal $\mathrm{Na}^{+}-\mathrm{K}^{+}-\mathrm{Cl}^{-}$ cotransporter activity and vasopressin-induced trafficking are lipid raftdependent. Am J Physiol Renal Physiol 295:F789-F802. CrossRef Medline

Williams JR, Sharp JW, Kumari VG, Wilson M, Payne JA (1999) The neuronspecific $\mathrm{K}-\mathrm{Cl}$ cotransporter, KCC2. Antibody development and initial characterization of the protein. J Biol Chem 274:12656-12664. CrossRef Medline
Woodin MA, Ganguly K, Poo MM (2003) Coincident pre- and postsynaptic activity modifies GABAergic synapses by postsynaptic changes in $\mathrm{Cl}^{-}$ transporter activity. Neuron 39:807-820. CrossRef Medline

Zhao B, Wong AY, Murshid A, Bowie D, Presley JF, Bedford FK (2008) Identification of a novel di-leucine motif mediating $\mathrm{K}(+) / \mathrm{Cl}(-)$ cotransporter KCC2 constitutive endocytosis. Cell Signal 20:1769-1779. CrossRef Medline

Zhou HY, Chen SR, Byun HS, Chen H, Li L, Han HD, Lopez-Berestein G, Sood AK, Pan HL (2012) N-methyl-D-aspartate receptor- and calpainmediated proteolytic cleavage of $\mathrm{K}^{+}-\mathrm{Cl}^{-}$cotransporter- 2 impairs spinal chloride homeostasis in neuropathic pain. J Biol Chem 287:33853-33864. CrossRef Medline 